\title{
Intonation on the individual
}

\section{Introduction}

As archaeologists working in contemporary theoretical paradigms, we tend to look for the individual through discourses and cultural performances around personhood, material culture, gender or age (Fowler, 2004; Lucy, 1997; Martin, 2014; Felder, 2015). In part this research priority is driven by a twenty-first century perspective, which focuses on social questions through a lens of contemporary individualism. However, the individual may not always have been created within this frame. Who is the individual within a historic lineage, a large household or an extended kinship system, for example? Additionally, despite the specificity of archaeological discourse, social categories do not intersect cleanly with each other and there can be significant overlaps and grey areas.

In the shoe example discussed in the first chapter, a skateboarder had a particular pattern of wear to their skate shoes, and this acted as a semiotic device recognisable to other skaters. However, skating is not just an identity; it is also a pastime and an attitude or a social activity (Hockey et al., 2013; Ingold, 2010). Similarly, like weapon use in the early Anglo-Saxon period, skating may expose a person to injury significant enough to cause skeletal trauma. Skating as an activity may be more common among members of certain ethnic or social/ economic groups, or genders. A professional skater, for example, might have achieved their status helped by their economic background, which allowed them time to practise, or because some value systems of classes or families valued the activity or sporting achievements where others did not. Moreover, an individual skater might be unique, defying the usual social, economic or attitude boundaries of others. Hypothetically, a skateboarder might be buried with the board they had used, but if the people making the decisions at the funeral were not themselves skaters they might not choose to include it, or they might position it without the knowledge of a skater. As an activity, skateboarding may take place 
outside of, or in parallel with, other identities. It may be linked to life course stages, practised by adolescents or young adults more than children or the elderly. A skateboarder might not be one at all times - for example, when returning home to family or to the household to eat, where their primary identity is that of son or daughter. Skateboarders might have different biological backgrounds, familial or ethnic, and so their bodies might be different heights and/or different shapes to those of their peers. They might socialise with other skaters and so might meet a partner though that activity and might marry that person, but they might also meet their partner though education, employment, social networks or family, or by prior arrangement. Skateboarding is a physical activity, a community and an identity. However, it is also an expression of individuality, and at the same time involves membership of a network of other skaters. But a person does not have to be part of that network to own a skateboard, to skate or to have skating paraphernalia placed in a mortuary context. An aspiration, a gift or a key relationship also might bring skating material culture to the grave.

Similarly, a weapon burial may be one part of an identity which is nested with others alongside social, ethnic or religious values (Hakenbeck, 2007b). A weapon may not mean the same thing in different graves. A sword, for example, may be part of a person's mortuary aesthetic and wrapped up with pluralistic expressions of personhood (Sayer et al., 2019). But would a weapon have been placed in the grave because the person was a warrior, because they occupied a specific social/economic rank, or because they belonged to a specific group, for example, a family with a tradition of weapon burial? How long did that 'tradition' last? Two generations, three, or more? Did having a weapon in the grave mean that that person had used it in life? Or that they could have used it in life? Were they witnessed with it or a similar weapon? And was weapon ownership, practice and use more common in some social or economic groups than others? (Sayer et al., 2019; Brunning, 2017; Martin, 2014; Felder, 2015). Were people who used weapons routinely associated with them? In short, what could a weapon embody - masculinity, war, danger, protection, physical prowess, youth, storytelling, heroics, banditry, wealth, heritage, hunting, camaraderie, safety? Is it all of those thing to all people, or some of those things to some people? Material culture can change the body, either with its presentation or by influencing its shape and appearance - muscles and calluses, for example - but for a weapon to change the body it had to be used, and it could not be entirely symbolic or passive. However, the association with weaponry post mortem may be about attitude and lifeways, as much as about the physical use of that weapon. An Anglo-Saxon slave might have owned a spear and 
used it regularly; s/he may have engaged in hunting for food, fighting for protection or participating in aggressive raiding and battles. As a result, the way in which a spear or sword intersected with mortuary identity may have been more dependent on who buried them and their attitude.

With these pluralistic questions in mind this chapter explores biological data because, importantly, it is the body that allows us to penetrate these points of social attitude. At Apple Down, for example, there are two burial configurations. The first group occupied a smaller mortuary space, which was returned to for generation after generation, and it employed a particular orientation for the graves that defined the aesthetics of that space and allowed it to be identified. These people from the first configuration buried their dead with weapons or brooches, and they were buried alongside infants and children. The lives of the people in the second configuration on average were shorter: they did not bury their dead in one space, but instead chose to do so in a chronological sequence, one after the other in a clockwise pattern around the cemetery. They used the mortuary space differently; they may also have had different diets, different biological heritages and different relationships, or had different attitudes towards marriage, the selection of sexual partners or the creation of a union between couples. The differences visible within the cemetery space, and within the bodies of the dead, resulted from different decisions and attitudes. It is by exploring the archaeology of lifeways and attitudes together that we may begin to see where material culture and physical practices intersect.

To explore lifeways and attitudes together, this chapter looks at the presence of skeletal pathology, in particular at trauma and damage caused by work or injury. This chapter looks at diet via isotope data and then at the body through height and teeth metrics. All of these are combined with a detailed chronological, material and spatial examination of the cemeteries under investigation in order to look at social attitudes, which can be explored by understanding a group's exposure to risk or their attitude towards biological relatedness. The actions and material expression of mourners at the graveside might tell us about the individual, but how that person's lived experience compares to others' unlocks a whole range of alternative multi-scaled interpretations. Diet and trauma may provide insight into lifeway, whereas height and teeth metrics may reveal a degree of relative biological connection. 


\section{Lifeways}

The challenge presented to the social archaeologist is that the evidence available has resulted from a multitude of simultaneous social and environmental factors. It is the prerogative of natural scientists to isolate a particular process for examination, but inevitably this can oversimplify the situation, reducing the complex or pluralistic nature of society. In this section we will be looking at evidence from the body, and situating that within an examination of social situations. For example, rather than investigating the medical or social cause of skeletal trauma and the individual experience, we examine with whom it is found, alongside the mortuary technologies already identified in the preceding chapters. Despite its title, this chapter is not about the individual, but it uses individuals as the building blocks with which to examine the community of which they were a part. By first identifying where different lifeways, and different attitudes, arose it is possible to explore in more depth the place of the individual within early Anglo-Saxon lived experience.

Of the 121 inhumations at Apple Down, twenty showed evidence of skeletal trauma - specifically fractures, periostitis (bone infections) or swollen limb-bone shafts; interestingly, only four of these 121 graves (nos. 14, 19, 28 and 67) belonged to configuration A (as defined in Chapter 1). However, the prevalence of arthritis did not share this pattern, because seven of the thirty-six configuration A burials and twelve of the seventy-five configuration B burials had osteoarthritis. The percentage of individuals with arthritis was very similar to that seen at Finglesham (see below) but, unlike Finglesham, at Apple Down we can conclude that all of the individuals were exposed to a similar amount of risk for acquiring this pathology, for example, exposure to injury, or repetitive or manual labour. Nonetheless, those people belonging to the less well furnished and peripheral burials of configuration B were exposed to a higher risk of physical injury than their peers in configuration A, evidenced by an increased frequency of fractures seen among this group. Perhaps both groups worked, but for the individuals found in a configuration B burial there was a more immediate risk of physical trauma associated with their lifeway; perhaps the labour they engaged in was heavier or more dangerous.

This pattern shows that there were at least two different lifeways present within this site. The configuration A burials included a higher proportion of adults aged over 45 and, if all things were equal, their longer lifespans should have resulted in a higher, not lower, incidence of osteoarthritis and trauma. The configuration A area included a greater proportion of children and furnished graves, and it also had a different chronological character to configuration B. Notably, the individuals 
associated with configuration A created genealogies within the immediate, densely packed inhumation space. These people returned time and again to bury their dead, whether elderly, adult or child, a pattern also seen at Orpington and West Heslerton. Configuration B burials, by contrast, did not seem to place emphasis on returning to the same spaces, nor on the locations of children's graves. This group carried out more dangerous work, labour which changed their physical bodies; they dressed their dead differently, placing emphasis on more mundane objects like beads or buckles, and they placed less emphasis on familial or ancestral history than did their peers. Their cemetery space developed with a chronological character, and it appears to have been a more functional space, not loaded with the same symbolism found with configuration A burials.

At this point it is worth revisiting Finglesham early Anglo-Saxon cemetery in detail because there were also a number of different lifeways evidenced in this large cemetery. Finglesham contained 254 excavated inhumations, ranging across the sixth and seventh centuries; these clustered at $4 \mathrm{~m}$ and were divided into four plots, A, B, C and $\mathrm{D}$, with sufficient gaps between them for us to be confident of their deliberate separation (see Chapter 4, Figure 4.15). A number of burials at Finglesham had medium-sized or small barrows over them, and some of these graves were furnished burials, while others were less well furnished. Finglesham also contained graves which used integral features, as at St Peters (Chapter 4), and it is notable that these graves with integral features were less likely to have been robbed ( 7 per cent). Indeed, there is strong evidence to suggest that the differences between graves was an expression of social differences. In addition, we saw in Chapter 4 that there were three distinct rituals within the cemetery: 1) burials with gendered objects or burial wealth in flat graves or barrows; 2) burials with integral features and objects, but rarely displaying gender identities; 3) burials in flat graves with limited or no gravegoods.

This was a complex cemetery and the differences in burial ritual highlight cultural differences that were markers of social divisions inherent in the community. However, these differences were not easily witnessed in the physical bodies of the deceased, suggesting similar lifeways within, but not necessarily across, the community who used Finglesham. These differences in lifeways are apparent in two types of evidence - skeletal pathology (Figure 5.1) and dental pathology (Figure 5.2). The majority of cases of identifiable skeletal trauma were seen in plot B, which also had the longest internal chronology of the groups within the cemetery. The skeletal trauma was evident in the form of activity-related trauma, manifesting most evidently in the presence or absence of arthritis among the burials. However, witnessing this difference is tricky. For example, 


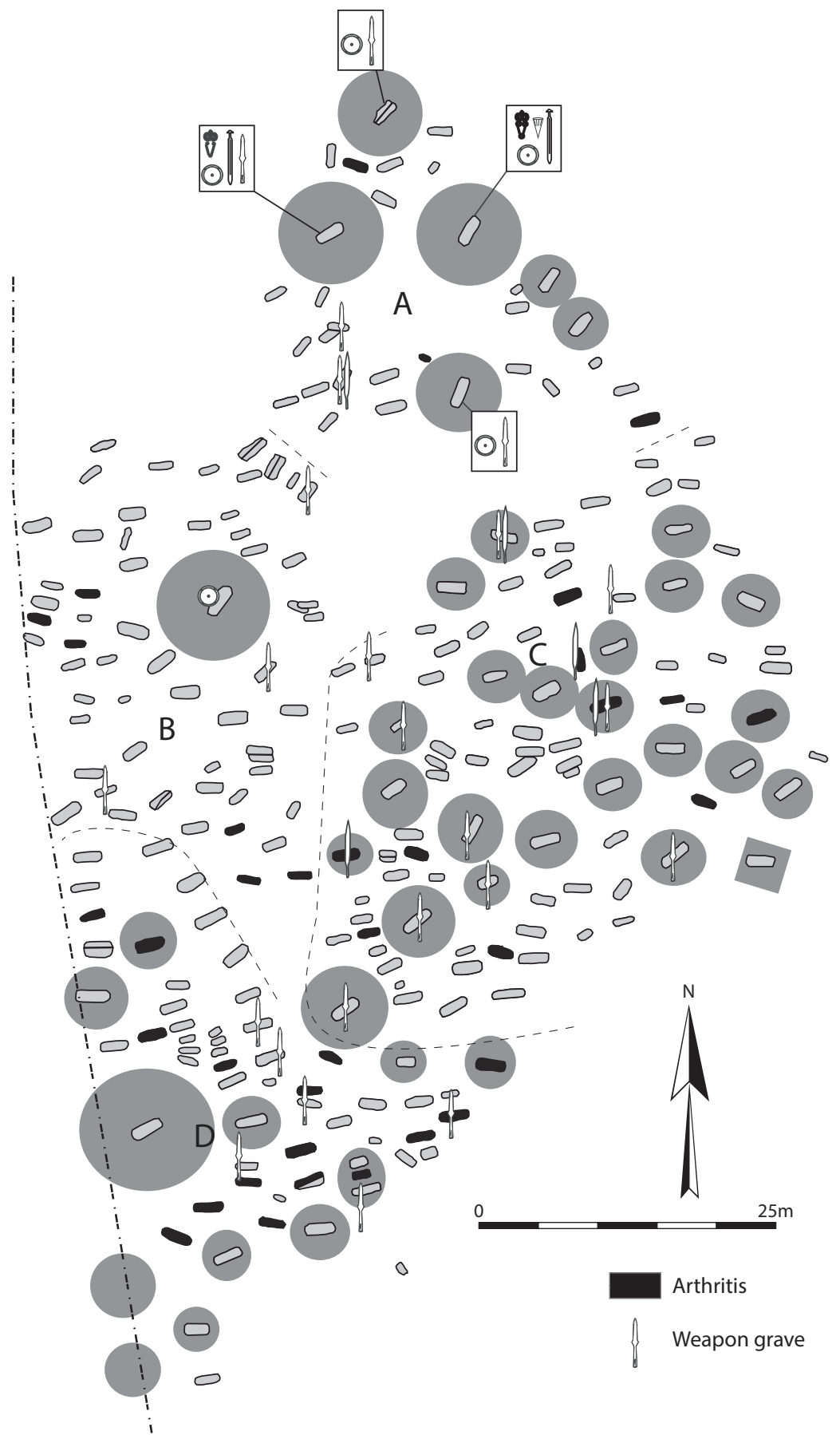

Figure 5.1 Finglesham, Kent: the distribution of arthritis and weapons. 


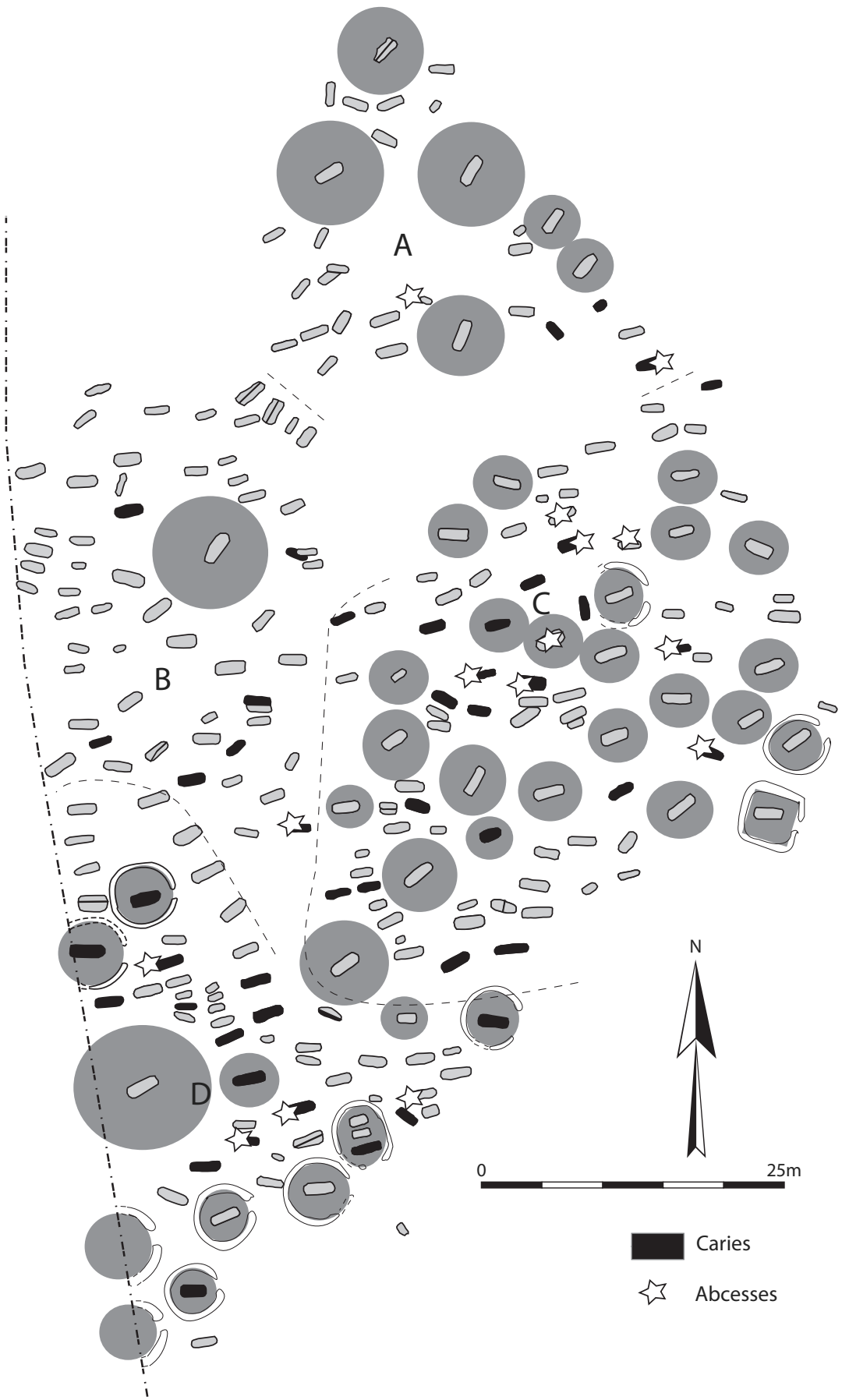

Figure 5.2 Finglesham, dental pathology: caries and abscesses. 
there is no significant difference between the numbers of individuals with weapons and the numbers without, or those with arthritis found in flat graves, in graves with integral features, or under barrows. Each category has a proportion of around 16 per cent of the population who manifest arthritis. Similarly, 15 per cent of the male population had arthritis, and around 15 per cent of weapon burials showed evidence of arthritis. However, this flat patterning is not repeated between the spatial groupings, and there were patterns in the frequency of arthritis found between burial areas. In plot A three of thirty-two graves had arthritis, although preservation is poor in this plot (Figure 5.1). In plot $\mathrm{B}$, six of sixty-four grave inhabitants had arthritis, whereas in plot $\mathrm{C}$ ten of ninety-five had arthritis. In plot $\mathrm{D}$, however, sixteen of sixty graves showed evidence of arthritis.

This is a ratio of around 10 per cent in plots A, B and C, and 27 per cent in plot $\mathrm{D}$; thus in plot $\mathrm{D}$ arthritis was found with almost three times the frequency. These data give a $p$-value of 0.013537 using Pearson's chi-square test, and this result is significant. Note that this test is appropriate for a $4 \times 2$ contingency table, comparing presence and absence of arthritis in each plot; however, given the poor preservation in plot $\mathrm{A}$ it has also been calculated for $\mathrm{B}, \mathrm{C}$ and $\mathrm{D}$, and this comparison gives a $p$-value of 0.007963 and so is also significant. Pearson's chi-square test is appropriate where there are values over 5 and with a significance of 0.05 . Arthritis was therefore more likely in the plot $\mathrm{D}$ graves because of patterns in cultural activities and was not due to chance. Just as with Apple Down, these individuals were exposed to a greater risk of developing the disease because of their differential exposure to high-risk activity, work or injury. Therefore in both cemeteries there was evidence of different lifeways, which corresponds to the spatial organisation of the sites and not directly with just the presence and/or absence of material culture. Notably, however, plot D was also the least wealthy part of the cemetery, just as at Apple Down.

Unfortunately, good-quality skeletal data are not available for the earliest phases of the excavation at Finglesham and this can make comparing skeletal particularly dental characteristics in plot A and B more challenging. Nonetheless, there are important differences in dental pathology between plots C and D. Overall, dental pathology showed similar results to arthritis. Dental caries, for instance, had a limited frequency with no particular patterns (Figure 5.2). The thirty-seven examples were proportionally distributed between plot C (20 of 95) and plot D (17 of 60). Abscesses were similar again, with eight examples in plot $\mathrm{C}$ and four in plot D. However, enamel hypoplasia was found in fifteen of the sixty graves ( 25 per cent) in plot $\mathrm{D}$ whereas in plot $\mathrm{C}$ just nine of ninety-five graves (10 per cent) showed similar evidence (Figure 5.3). 


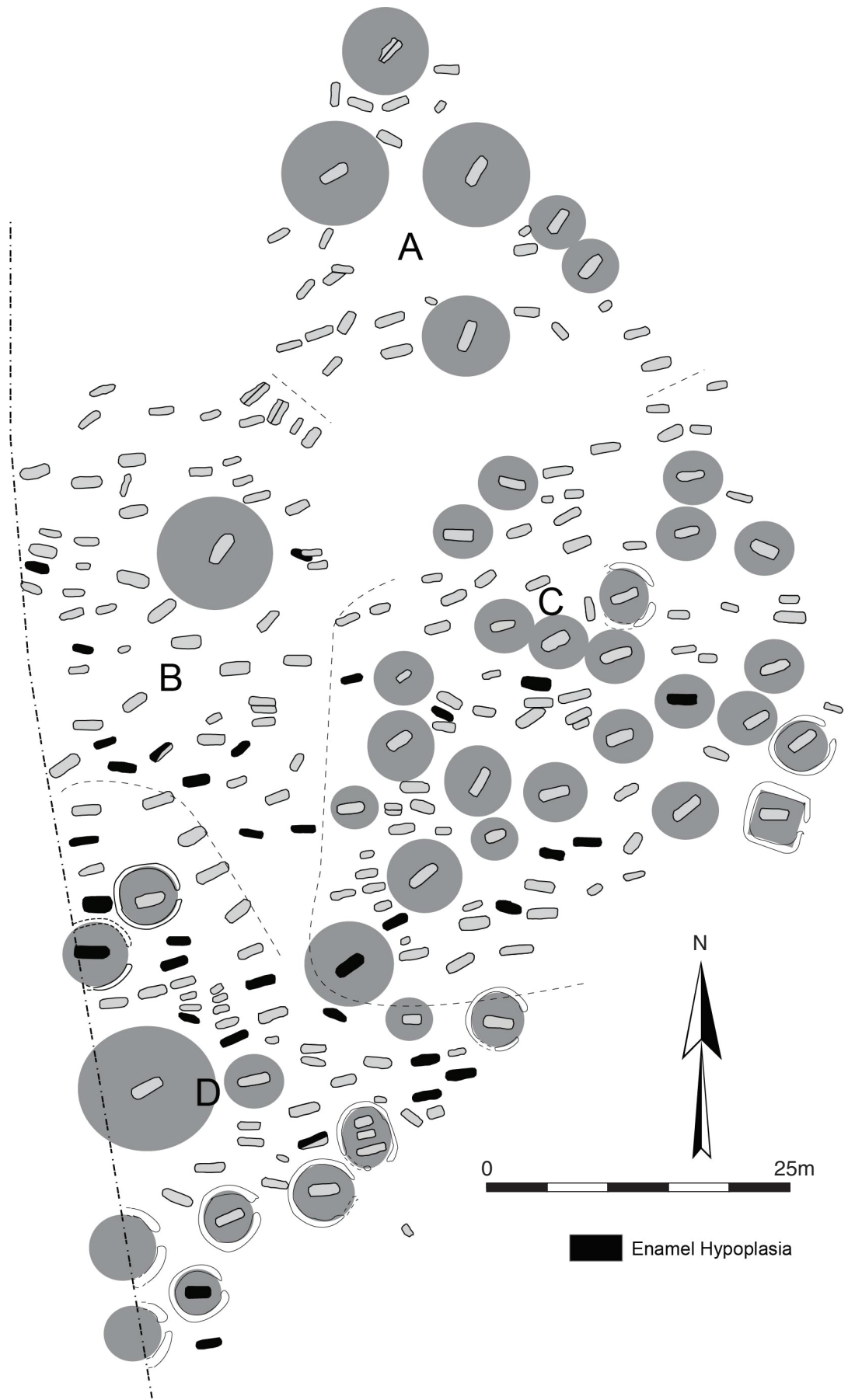

Figure 5.3 Finglesham, dental pathology: enamel hypoplasia. 
Enamel hypoplasia occurred with more frequency in plot D. The numbers were small and were thus analysed with Fisher's exact test, which provided a $p$-value of 0.0122 . As a result, this pattern is not random; it is significant and should be understood as the product of cultural activity. Equally, of the thirty-four total cases of enamel hypoplasia, only four occurred among the individuals that were buried under barrows. In other words, 88 per cent of cases of enamel hypoplasia were found on individuals in flat graves; proportionally there were four cases in thirty-nine (10 per cent) in barrows and thirty-three ( 15 per cent) in the 217 flat graves, but, with a Fisher's exact test $p$-value of 0.62 , this difference does not have statistical significance and should as a result be seen as the product of chance. Enamel hypoplasia is evidence of periods of nutritional stress or disease during infancy and childhood (Roberts and Manchester, 2005). It is not unexpected in an early medieval population, but it is important that this has been identified in significantly higher proportions in plot $\mathrm{D}$ than in plot $\mathrm{C}$, suggesting a difference in childhood diet between the populations of the two areas. As a result, it seems reasonable to conclude that these childhoods were somewhat separate, or at least that access to resources and consumption practices were not shared between these groups of people.

The cemetery at Finglesham contained evidence of at least two different life experiences, and these were distinguished by the use of one plot or another within the cemetery. The individuals in plot D were exposed to a higher risk of acquiring arthritis, probably through exposure to physical labour. It is likely that the population of this part of the cemetery was also exposed to nutritional stress or disease in childhood, and in thirty-four examples this manifested as enamel hypoplasia. This developmental deficiency was more frequent in plot $\mathrm{D}$, the inhabitants of which had a poorer childhood diet compared to the rest of the cemetery population. These conditions did not physically manifest in the skeletal remains of all of the people in plot $\mathrm{D}$, but the increased frequency suggests that the risk of acquiring arthritis or enamel hypoplasia was much higher among this specific group because of their lived experience. Thus, if the plots are evidence for different households, or corporate groups, then these groups experienced different lifeways, and there may have been limited intersection between these lifeways. Although high-wealth graves from the whole cemetery were as likely to contain individuals with arthritis or enamel hypoplasia as not, it is conspicuous that the most-wealthy graves were absent from plot D. Deprivation and hard repetitive work were characteristic of the community at Finglesham, and at other early medieval sites such as Apple Down, because these conditions were prevalent across the population as a whole. Nonetheless, the people who were buried in plot D had 
different physical and cultural experiences to those who were found in plots A, B and C.

Great Chesterford, Essex, is another site with evidence of multiple lifeways within the mortuary population. Great Chesterford was excavated between 1953 and 1955 and a large population was uncovered, with 167 individuals found at the site. This cemetery was notable in a number of ways; in particular, there was a larger proportion of women, infants and children than expected. Unfortunately, only part of the cemetery was excavated. Tony Waldron analysed the human remains, focusing particularly on the pathology and on preservation. His more detailed notes and appendix are available as a Historic Buildings and Monuments Commission of England report, no. 89/88 (Waldron, 1994). These data were reviewed and added to work published by Sarah Inskip (2008), who noted the high degree of tuberculosis among the remains.

As we have seen in previous chapters, Great Chesterford was notable because the aesthetics of the space combined material culture, the orientation of graves and clustering, which were used to define and separate a series of plots and burial areas. In area A there was a central area defined by inhumations of different orientations, which included the wealthiest graves in the cemetery. In area B the core graves were well furnished, and area $\mathrm{C}$ consisted of a series of equally spaced, but contrastingly oriented, burials. The graves in area D were widely spaced and poorly furnished. As with the examples at Finglesham and Apple Down, the individuals in this cemetery experienced different lives and chose to bury their dead differently. This was evidenced in the prevalence of arthritis, osteophytes and fractures. Osteophytes are bony projections associated with the degeneration of cartilage at the joints, and are caused by localised inflammation, for example, from degenerative arthritis or tendonitis. As a result they are related to osteoarthritis in their cause, and are primarily the result of stress within the physical environment. Each of the individuals in plots $\mathrm{A}, \mathrm{B}$ and $\mathrm{C}$ had similar proportions of these skeletal traumas, whereas area $\mathrm{D}$ had proportionally twice as many instances of arthritis, osteophytes and fractures (see Table 5.1). Indeed, where skeletal preservation was good enough to analyse, 46 per cent of the individuals from area D showed evidence of arthritis. In effect, this means that people in this burial area were twice as likely to develop this condition as those in areas A, B and C. Additionally, 53 per cent of these individuals had developed osteophytes and 23 per cent were found with fractures, having been exposed to more than double the risk of physical injury as those individuals in areas $\mathrm{A}, \mathrm{B}$ and $\mathrm{C}$, and were treated differently in death. A chi-square test was used to examine if the proportion of individuals with pathology in area $\mathrm{D}$ is notably higher than the proportion in areas $\mathrm{A}, \mathrm{B}$ or $\mathrm{C}$. The $p$-value for this test, using data 
Table 5.1 Skeletal trauma at Great Chesterford

\begin{tabular}{lcccc}
\hline Grave area & \% of graves A-D & Arthritis & Osteophytes & Fractures \\
\hline$A$ & $(20) 29 \%$ & $(7) 25 \%$ & (7) $35 \%$ & (1) $5 \%$ \\
$B$ & $(13) 19 \%$ & $(2) 15 \%$ & (3) $23 \%$ & $(1) 8 \%$ \\
$C$ & $(22) 32 \%$ & $(4) 18 \%$ & (8) $36 \%$ & $(2) 9 \%$ \\
$D$ & $(13) 19 \%$ & $(6) 46 \%$ & (7) $53 \%$ & (3) $23 \%$ \\
predicted & $100 \%$ & $25 \%$ & $36 \%$ & $10 \%$ \\
\hline
\end{tabular}

from Table 5:1, was $p=0.006$, which is significant. As a result, we can conclude that the people from area $\mathrm{D}$ were exposed to significantly more risk within their lived experience, and these people also chose a different location to bury their dead. In this case, as with the Apple Down and Finglesham plots, we see the cemetery spaces related to groups of people with different lived experiences.

Arthritis is caused when joints are not able to withstand the stresses repeatedly applied to them, for instance through repetitive work, and joint injuries also greatly increase the risk of acquiring arthritis. Individuals such as the occupant of grave 160 from Great Chesterford showed evidence of secondary osteoarthritis of the elbow following fracture (Waldron, 1994: 57). Occupational stress has been seen from sites such as the Mary Rose where, from a total of 110 individuals recovered from the submerged wreck, fifteen individuals showed evidence of os acromiale (non-fusion of the acromion, a bony process on the scapula). This may have been linked to the use of the rotator cuff (a group of muscles and tendons that stabilises the shoulder joint); the injury/deformity is specific to archery (Stirland, 1986; 2000). Similarly, arthritis may be caused by a mixture of environmental factors resulting from the gradual wear of cartilage in the joints, joint inflammation and imperfect repair mechanisms in response to injury (Roberts and Manchester, 2005). As a result, patterns in the frequency of degenerative joint diseases can be used to differentiate specific occupation patterns within a community, but each of these individuals had different conditions. Therefore it is more appropriate to explore different lifeways resulting in increased exposure to, or frequency of, trauma - that is, that some groups of people were exposed to a greater degree of risk (Samut-Tagliaferro, 1999; White et al., 2012: 441; Johnson, 2008). Arthritis is found at different locations on the skeleton and it has a less specific cause than the os acromiale seen on the Mary Rose. As a result of this ambiguity it possible to suggest only that the individuals of Finglesham and Great Chesterford were exposed to a higher risk of acquiring joint injury. This increased risk probably resulted from exposure to injury, as well as repetitive manual labour. 
Importantly, there was no correlation between weapon burials and arthritis at these three sites. That is interesting because it means that the semiotics associated with weapons, and probably other gravegoods too, crossed these experiential boundaries. Despite this, the well-furnished, or wealthiest, graves were absent from plot D at Finglesham, where most trauma was found. At Apple Down, and at Great Chesterford too, exposure to a high risk of joint trauma and the absence of wealth in the graves seems to have correlated. It is unfortunate that these numbers are small, but these are the sizes of the cemeteries and the populations we have to work with. Nonetheless, despite these small samples, the patterns are strong, and correlate with spatial as well as wealth differences within the mortuary populations. In combination, these differences are striking and evidence of the different lived experiences. Patterns in skeletal pathology do not seem to correlate with individual variations, for example, the presence or absence of a weapon, but with corporate groups across community-level dynamics. The differences in lifeways that we have seen at Finglesham, Apple Down and Great Chesterford overlapped with differences in mortuary expression. Different corporate groups shared different values which contributed to how they chose to bury their dead, how the deceased were commemorated, and how cemetery space was used. These differences in attitude and in lifeways were embedded in the community for generations and changed only slowly over hundreds of years.

\section{Parallel lifeways}

Unfortunately, the majority of early Anglo-Saxon cemeteries have poor preservation, or else (in many cases) the skeletal data have not been recorded to modern standards. This chapter has described a series of sites with evidence for internal differences within the distribution of skeletal or dental pathology, and these corresponded to cultural differences in mortuary treatment at these sites. In each of these cases the numbers were relatively small, reducing confidence in the statistics. However, Fisher's exact test was used to test for significance, a reliable statistical approach where the numbers are low, i.e. below five, and where chi-square would not be accurate. As a result, we can be confident that the differences seen at Finglesham, Apple Down and Great Chesterford were actually the product of lifeway differences between co-operating but separate or unequal corporate groups. Reassuringly, the differences between these groups included skeletal trauma, spatial location and/or variation in the expression of material wealth, and therefore we might infer that these patterns were behavioural and related to differences in lifeways and attitudes to mortuary practice or expression. This is evident because in 
each site there were distinctly different ways of treating the dead, who were found in different locations, on different orientations, and with different patterns to the chronology of burial. At Apple Down and Great Chesterford this also included or excluded different age groups, more specifically, children. Together these differences and the pathology point to evidence of different lived experiences. Importantly, however, not all cemeteries contained evidence of separate lifeways.

The Anglo-Saxon cemetery at Berinsfield is a good example of a cemetery with the same proportions of pathological evidence between differentiated types of burial. Berinsfield consisted of two contemporary collections of graves and both contained a core group of inhumations, and although these were of similar dates they spanned different generations (Sayer, 2010; see Figure 5.4). The burials at Berinsfield have been dated using the typology method because they were largely too early to reliably use the radiocarbon method - see Chapter 4, and Sayer, 2007. Graves 91, 102, 104 and 107 were part of the northern core and all dated to the early sixth century. Similarly, the southern core burials, $51,53,54$ and 66, also had a predominantly early/mid-sixth-century date. The exception was grave 52, early seventh-century in date, which was placed on a different orientation, an aesthetic way to distinguish it from its predecessors. The well-furnished burials at Berinsfield were all contemporaneous; however, in the northern cluster inhumation 91 was buried AD 450-566 and was aged 17-25, whereas grave 102 had an identical age range but was interred in the early sixth century. Inhumation 107 was buried AD 500-66 and was of a similar age. Grave 104 was buried between the early and mid-sixth centuries and was also aged between 17 and 25. In the southern group of inhumations grave 51 was a male aged $15-25$ years, interred between the later-fifth and sixth centuries, whereas grave 53, buried AD 500-66, was aged between 24 and 35, and burial 54, dated to the later-fifth to early sixth centuries, was aged between 25 and 36. The comparison of biological data and chronological information illustrates that these individuals had contrasting age and chronological characteristics, and so we might conclude that these core areas were returned to repeatedly, generation after generation, for three or four generations. These were places to bury a particular group of people and included one or two individuals from each age cohort, irrespective of gender (Sayer, 2010).

The presence of trauma pathology at Berinsfield is also important, because it was very different to that seen at Finglesham, Apple Down and Great Chesterford. Seventeen sets of human remains showed evidence for osteoarthritis, and these were distributed around the cemetery (Figure 5.5). There was no difference between burials, for example, in the type and style of gravegoods and osteoarthritis. Two of fifteen richly 


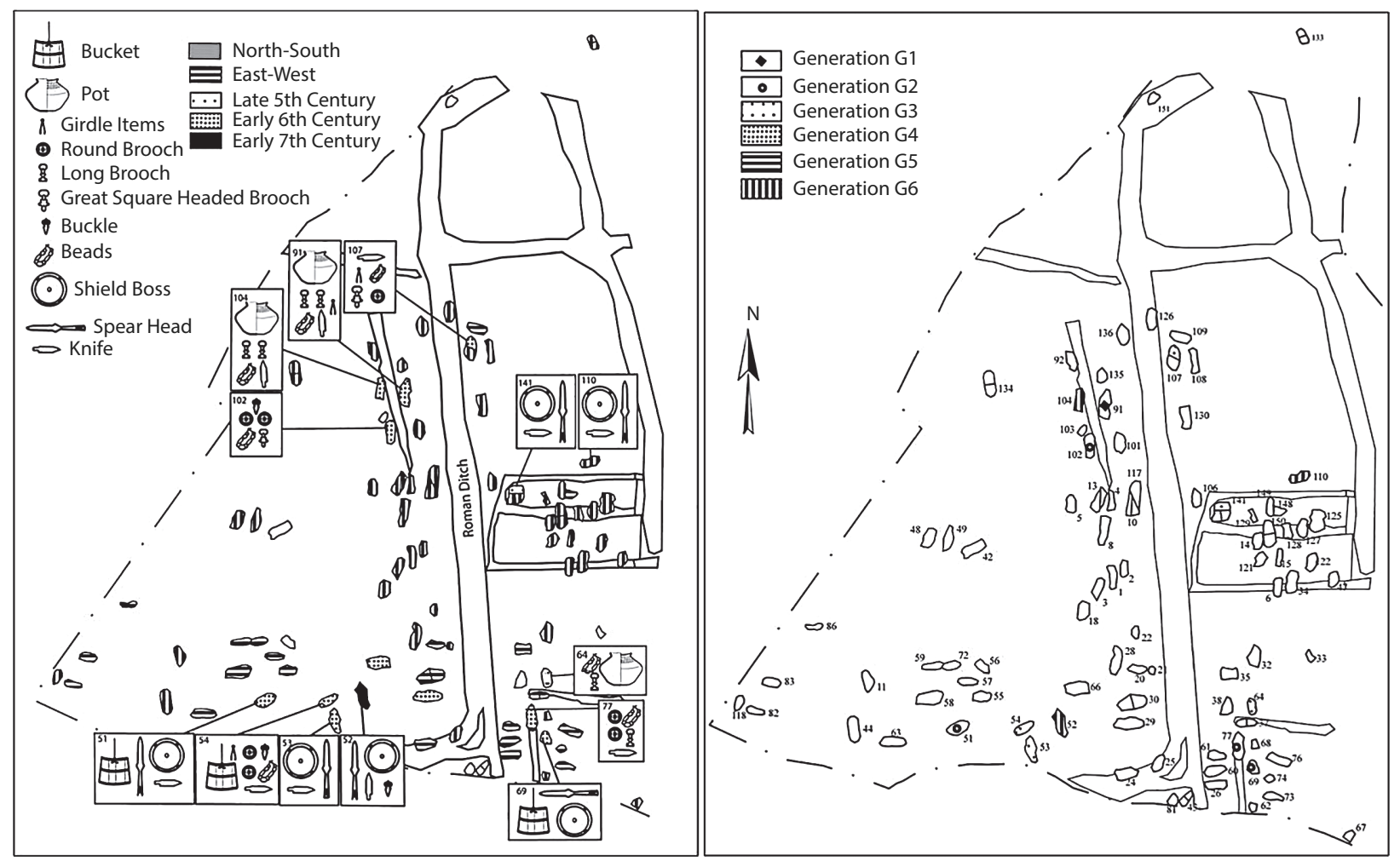

Figure 5.4 Berinsfield, Oxfordshire: the left-hand plan shows distribution and dating of wealthy burials; the right-hand map shows the generations that the burials belong to. The core burials were of similar dates but notably they spanned different generations (Sayer, 2010). 


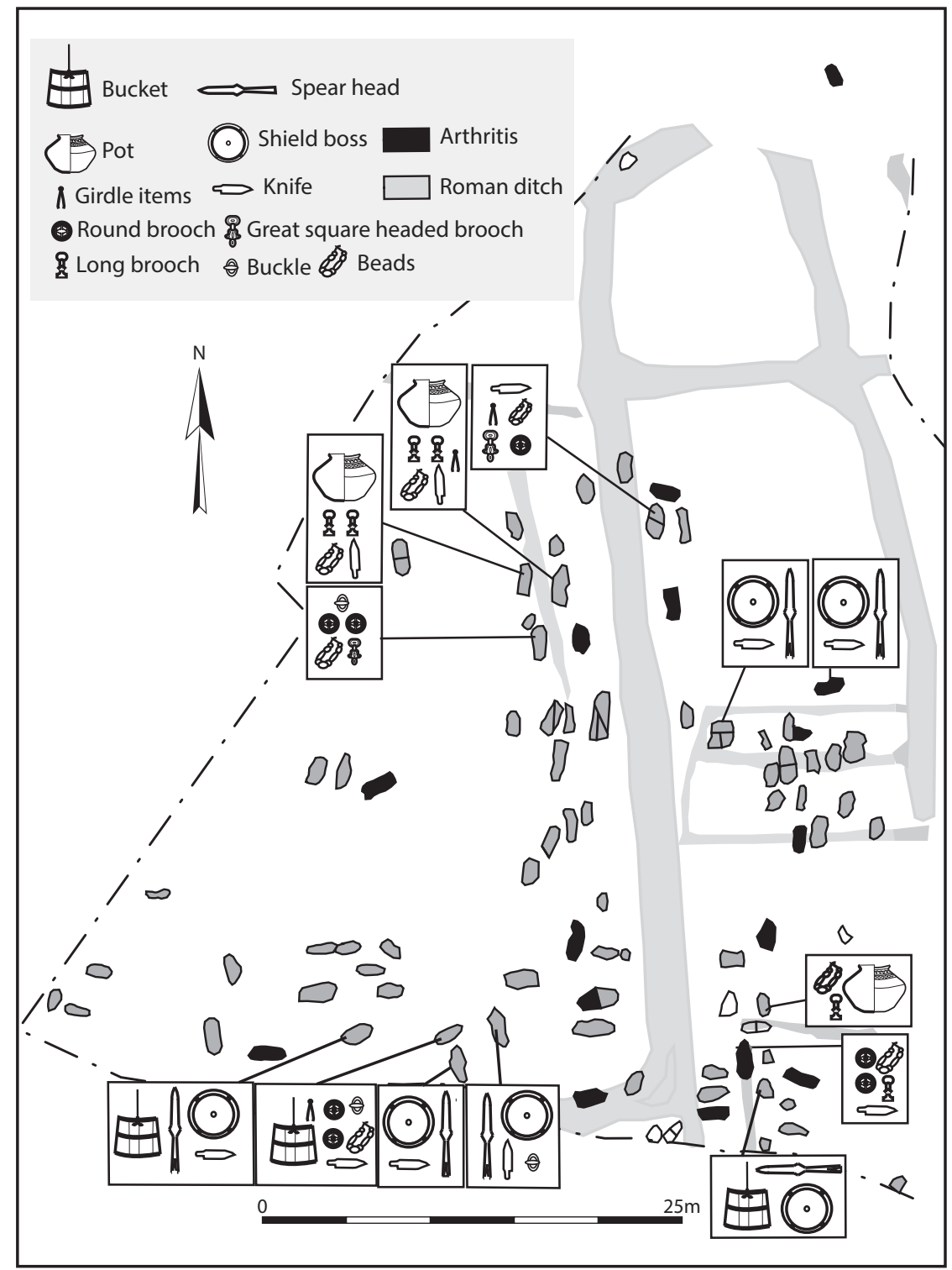

Figure 5.5 Berinsfield: the distribution of arthritis and artefacts.

furnished burials were found with osteoarthritis, and thirteen of eighty remaining burials for which data exists showed evidence of osteoarthritis. Fisher's exact test for this data gave a value of $p=1$, meaning that both richly furnished and poorly furnished burials had had identical proportions of arthritis. As a result, we can conclude that there were no 
independent factors which separated the experience of these individuals, based on gravegoods. Equally, the forty-eight burials to the north of the site, which have a primary N/S orientation, included seven individuals with osteoarthritis. In the south there were nine such burials, from a total of forty-nine. The southern burials primarily display an E/W orientation. A Fisher's exact test of these groups gives a $p$-value of 0.79 which is not significant. As a result, we much conclude that there are no independent factors influencing the presence of osteoarthritis among these individuals. In short, the physical experience, and the lifeways, at Berinsfield were similar for the wealthier burials and the different burial areas.

Deal, like Berinsfield, has no obvious differences within the lived experience. The site was a sixth- and seventh-century cemetery and consisted of three visually separate groups of graves around a Bronze Age barrow. Two plots, A and B, were contemporaneous and sixth-century in date. The third plot, C, was later-sixth- and seventh-century. Plots A and $\mathrm{B}$ were organised in similar ways. Plot $\mathrm{A}$, the spatial group southwest of the ring ditch, was a collection of early burials, five of which were similar - inhumation 33, a female adult, was interred in the early sixth century. Burials 17 and 97 were both male and had lived to an age of between 35 and 45 when they were interred in the mid-sixth century. Brugmann (Parfitt and Brugmann, 1997: 106) distinguished between these two, placing them in different phases of local Kentish chronology: burial 17 in phase II and burial 97 in phase III. This provided a mid-sixth-century date for both burials but specifically 17 dated to AD 530-40 and burial 97 to AD 530-70. Graves 17 and 97 were probably consecutive and not contemporary. Inhumations 102 and 25b were both females interred in the mid-sixth century; $25 \mathrm{~b}$ was aged between 25 and 35, whereas burial 102 was aged between 35 and 45 years. These age and chronological characteristics suggest that these individuals were born around the same time, or belonged to a similar generation (Figure 5.6). Burials from a 'middle' generation included grave 40 which was a particularly well-furnished burial of a male aged between 35 and 45 , interred with a full weapon set, including a sword. Of a probably comparable generation was burial $105 \mathrm{c}$, a notably well-furnished female inhumation, aged between 35 and 45 at death. Both were interred in the mid-/later-sixth century and may have been of the same generation. From the latest generation there was just one inhumation, burial 64 , an 18- to 25 -year-old female interred in the mid-sixth century, before graves 45 and 107c. As a younger individual at death she may have been born some time before them both, perhaps dying when they were children.

Within plot B, burials from the early phase and north-east of and overlying the ring ditch, there were also three generations, which 

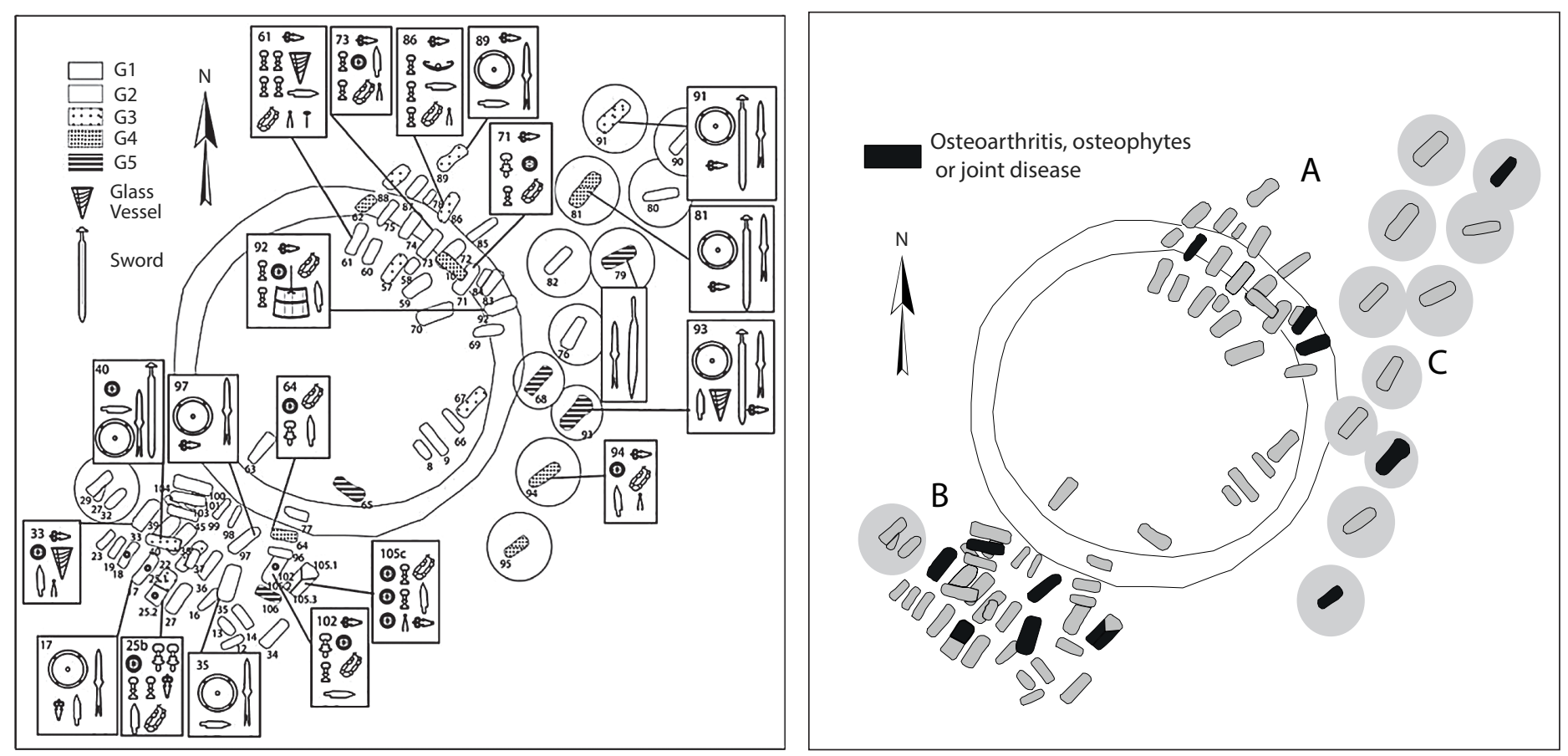

Figure 5.6 Deal, Kent: chronology and generations (after Sayer, 2010). 
showed a similar pattern to the contemporaneous plot A. The wealthiest burial consisted of a single early sixth-century female, inhumation 92 . Following on from this grave were three females interred in the early sixth century - burials 61 and 73 were both aged between 18 and 25 when they died. Burial 71 was a female who died in the middle of the sixth century and was of similar age. Age was the significant factor in all three of these burials, and it is very probable that in this plot was a series of consecutive burials of wealthy young women. The well-furnished burials from the latest generation included burials 86 and 89 , which may have been contemporary. These two graves were of a male aged 18 to 25 , buried early/mid-sixth century (in grave 89 ), and a female aged 45 plus and buried mid-sixth century (in grave 86); although they were of different ages at death, the two were probably from the same generation.

The second-phase burials were spatially separated from the earlier two groups described above. These latest graves were interred in a linear fashion underneath small mounds to the east of the ring ditch. This visual distinction indicated a change in the burial rite, and this change saw an increase in the number of male weapon burials. Despite this reorganisation, which emphasised a gender-specific expression, these male burials showed a similar pattern to the previous phases. Specifically, either one or two well furnished inhumations were found from each generation. The earliest well-furnished grave was a single sword burial, inhumation 91, a sub-adult buried in the middle-sixth century. Equally, grave 81 was a sword burial, but from a later generation. Grave 81 was interred in the later-sixth or seventh century, and was over 45 at death. A later group of well-furnished burials included a garnet brooch (burial 94 , aged 45 plus and interred in the early/mid-seventh century) and a single sword burial, (grave 93, also over 45 years old and also interred in the early/mid-seventh century). In the next generation there were two high-wealth burials from the same generation, and in addition a notable burial found with a seax, grave 79 . This burial was a young man interred in the later-sixth or early seventh century, who was probably from the same generation as burials 93 and 94. The aesthetics of the space changed, the emphasis shifted towards males, but attitudes toward the use of these spaces remained similar, with generations of burials returning to each of these plots to inter their dead as with phase one.

The pathology at Deal is similar to that from Berinsfield; thirteen individuals showed evidence for osteoarthritis, osteophytes or joint disease (Figure 5.6). These included eight from the thirty-one well-furnished graves, and three from fifty-four comparatively poorly furnished burials. However, using Fisher's exact test this difference is not statistically significant $(8: 23$ and $3: 51$ give a value of $p$-value $=0.64)$. Equally, when this is looked at by plot there are three graves with these pathologies versus 
twenty-two without in plot $\mathrm{B}$; three with versus twelve without in plot $\mathrm{C}$; and six with and forty without in plot A. Using a $3 \times 2$ contingency table and Pearson's chi-square test, these data have a $p$-value of 0.77 , which is not significant. In both cases, skeletal trauma was distributed across the cemetery in roughly comparable proportions (Figure 5.6). Similarly, seven of fifty-seven male burials showed evidence of skeletal trauma, and four of thirty-one females also showed evidence of skeletal trauma, with a Pearson's chi-square $p$-value of 1 and so also has no statistical significance, indeed, the differences are equally proportioned. Similarly, of the seventeen weapon burials at Deal, five showed evidence of skeletal trauma, whereas only two of the forty-nine weaponless burials had evidence of trauma. This result is significant, with a $p$-value of 0.04 . It may be that joint disease, and osteoarthritis in particular, are evidence of the higher risk of injury among martially inclined males. At Deal, this situation might be an individual choice, a decision to participate in the masculine lifeways that related to battle, such as one-on-one engagement or weapons practice. Nonetheless, these numbers are very low with just seven individuals with trauma distributed across both weapon and weaponless categories. As a result, we might question if this is a real variation or an artefact of preservation bias across the site. However, it remains important and especially so as it was a characteristic also seen at Apple Down. At these sites, there was a statistical correlation between the active inclusion with a weapon within the mortuary context, and physical change to the body. At Apple Down, non-participant males were larger (Chapter 1 and above), whereas at Deal the males found with weapon graves were exposed to greater risk of physical injury or joint disease.

\section{Isotopic evidence}

In the preceding section on pathology we saw two types of cemetery, those that contained groups of individuals with different lifeways and those containing groups of individuals with broadly similar lifeways. Existing skeletal isotope studies allow us to explore this distinction further, because they provide data which can be explored in a different way. The two most comprehensive studies are the comprehensive study of Berinsfield by Karen Privat et al. (Privet et al., 2002) and Bradley Hull's $\mathrm{PhD}$ thesis, in which he sampled a number of different cemeteries (2007). Both studies looked at dietary information using stable carbon and nitrogen isotope analysis, and both studies investigated social rank, age and biological sex. Hull also explored height and burial position in an attempt to find patterns in the data that could interpreted. Stable isotopes have been used routinely to explore diet in archaeological populations and have been used to explore subsistence practices and social 
status, as well as health and nutrition (Müldner, 2009). Carbon isotopes are used to explore the ecological foundation for the diet. Nitrogen, by contrast, shows where someone's main diet came from, marine versus terrestrial ecosystems, for example, displaying very different results.

As we have seen, Berinsfield consisted of two contemporary collections of graves organised around a series of Roman features, and these graves were organised into two groups buried on N/S and E/W alignments respectively. Both groups contained a core of relatively wealthy burials, but importantly trauma-related skeletal pathology was distributed around the site, as was evidence of osteoarthritis. Both types of skeletal damage were found in statistically equal proportions in both areas and in both the wealthier and less wealthy graves. The isotope data were similar, and Privat et al. concluded that 'the frequent consumption of animal products was not a privilege for any individual or groups at Berinsfield' (Privat et al., 2002: 788). However, there was a trend identified where individuals from burials of lower wealth had scores which showed an elevated level of $\delta 15 \mathrm{~N}$, suggesting that their consumption of forest/wild foods was higher. The Thames had a plentiful supply of fish and birds, and Privat et al. suggest that this isotope pattern may have resulted from higher consumption of these freely available resources, whereas the wealthier individuals feasted more regularly on omnivores as sources of protein, pigs for example (2002). This pattern was also seen by Hull at Worthy Park and Westgarth Gardens (Hull, 2007: 75, 176). There were no other patterns observed at Berinsfield; when the results from the two burial areas $\mathrm{A}$ and $\mathrm{B}$ were compared, there was no discernible difference between the two (see Figures 5.7 and 5.8). The slight difference seen in the $\delta 15 \mathrm{~N}$ was not significant, as proven in an independent $t$-test of the data, which produced a value of $p=0.433$.

As mentioned above, Worthy Park had a slight difference in nitrogen values between wealthy and less wealthy graves (Hull, 2007: 75). This may suggest that the individuals in poorer graves ate more fowl. Perhaps of more importance, however, was the statistically significant difference between carbon isotopes across the three burial areas identified earlier. In terms of height data, the $\mathrm{E} / \mathrm{W}$ weapon graves in plot $\mathrm{A}$ were the most homogeneous, suggesting that there may have been some sort of biological connection between these individuals, which was entwined in the orientation and material display of the dead (see below). No difference was seen in nitrogen isotopes, but carbon isotopes showed a statistically significant distribution between burial areas A, B and C (see Figures 5.9 and 5.10). An Analysis of Variance test (ANOVA) of the $\delta 13 \mathrm{C}$ data yielded a value of $p=0.044$, which was significant and must be the result of purposeful behaviours. The burials in area $\mathrm{A}$ had the highest $\delta 13 \mathrm{C}$ values, and $\mathrm{B}$ the second highest; the lowest scores were 


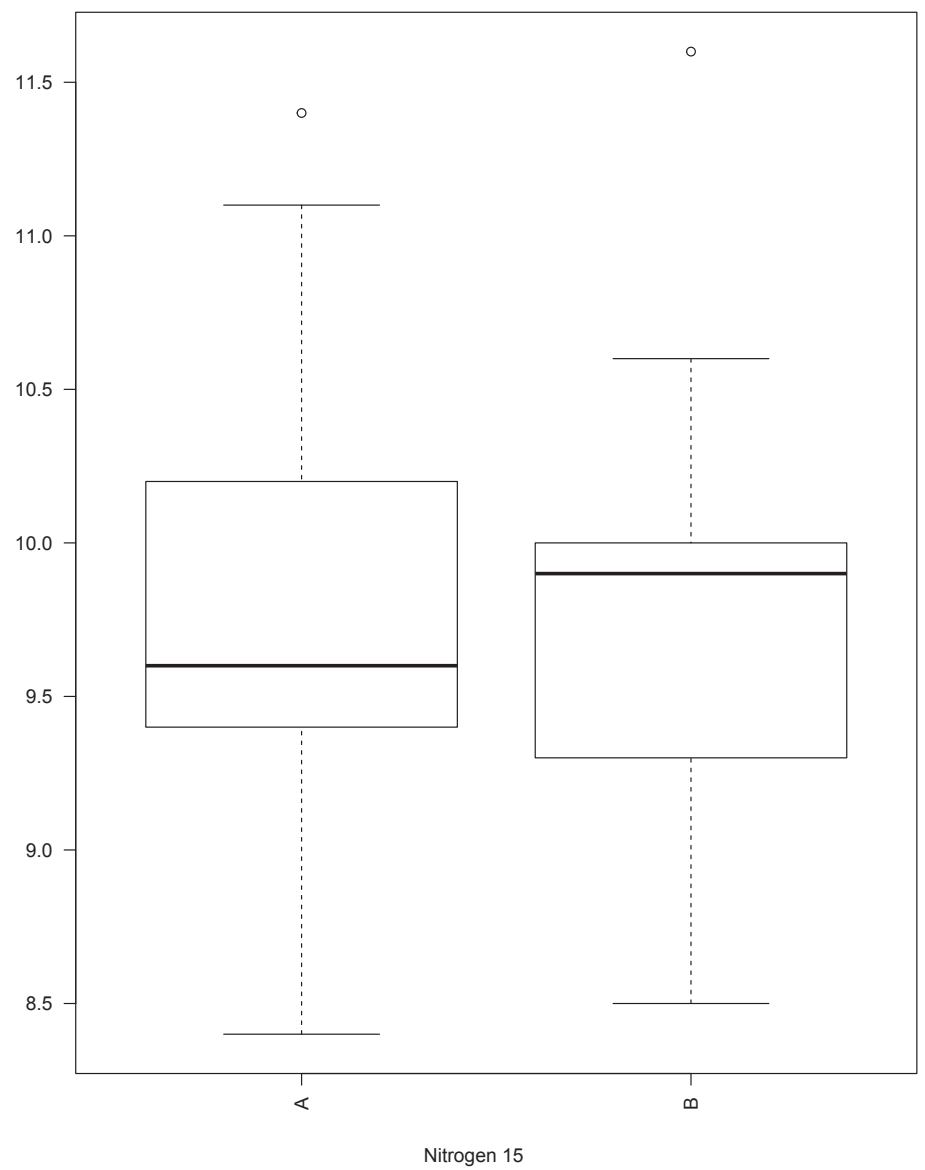

Figure 5.7 Berinsfield: nitrogen isotopes $\delta 15 \mathrm{~N}$ box plots by burial area. The range within these two burial areas A and B is very similar, showing no obvious dietary difference.

found in the burials of the small area C. Decreased levels of $\delta 13 \mathrm{C}$ may be caused by increased consumption of forest resources such as fruit, nuts and fungi, or via the consumption of pigs, whose food consisted of these things. Enriched $\delta 13 \mathrm{C}$ levels also may have come from the consumption of grains enriched with carbon, for example through the brewing process (Hull, 2007: 283, 296).

Patterns within these five cemeteries are important but it is only in combination with other types of data that we can start to infer identify or status differences within the living community. By using material, spatial and skeletal evidence we might begin to see differences that can be understood as differences of lifeways that might yield clues about social status. That does not mean social status as defined by the presence 


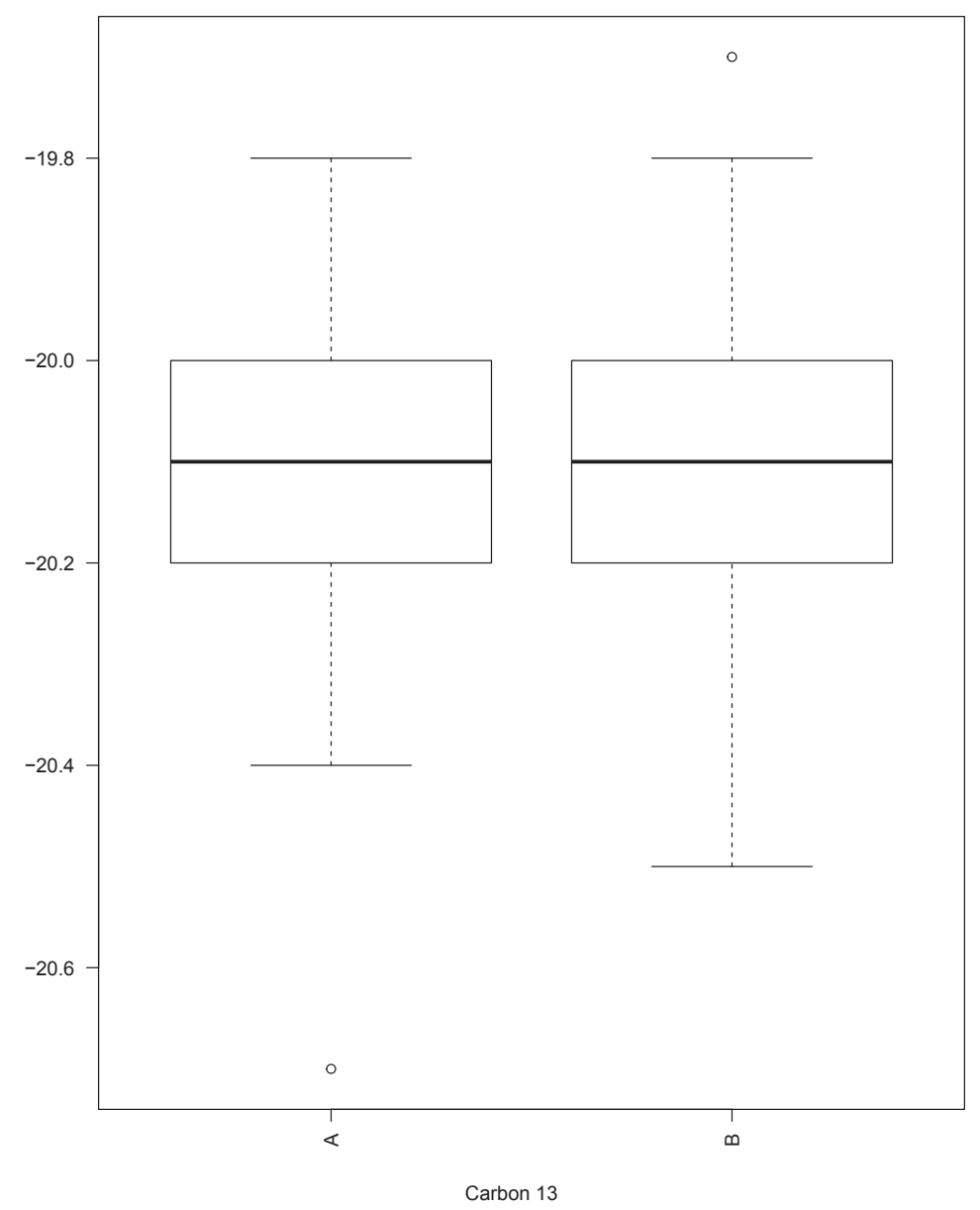

Figure 5.8 Berinsfield: carbon isotopes $\delta 13 \mathrm{C}$ box plots by burial area. Data from these two areas show identical results, except that the lowest result in plot B was was lower than that in plot A.

or absence of precious materials, or by the number of artefacts in graves, but status in dissimilar lifeways and in diverse attitudes towards the dead that indicate that there were a variety of ways of occupying the social landscape. Differentiation is important, and so is similarity. In the examples discussed above, Deal and Berinsfield, there were similar lifeways across the cemeteries suggesting that these sites may have been the mortuary spaces for two similar corporate groups. They defined themselves within the space using different mortuary technologies to create and recreate their own narratives. Ultimately, their bodies suggested similar experiences across both groups. As a result, there are at least two types of behaviour evident from early Anglo-Saxon 


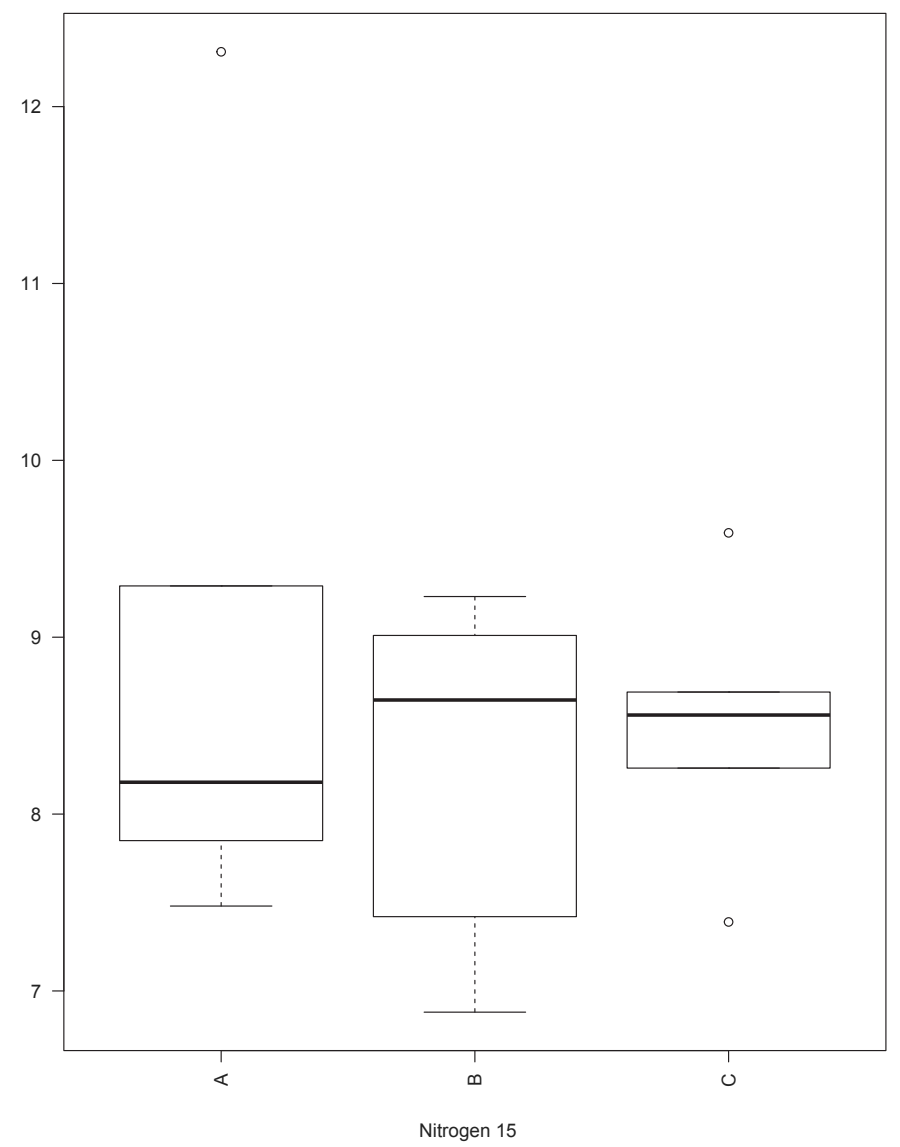

Figure 5.9 Worthy Park, Hampshire: nitrogen isotope $\delta 15 \mathrm{~N}$ box plots by burial area. The results from these three burial areas are very similar, showing no obvious dietary difference, though the range between highest and lowest results was far smaller in C.

cemeteries: those with broadly comparable lifeways/attitudes, and those in which there was a greater degree of social hierarchy. It is in the different treatments of the dead at Apple Down, Finglesham and Great Chesterford that we can see variations in lifeways. At Great Chesterford, there were three spatially defined groups of graves that shared similar skeletal data. Here the material differences suggested different ways of generating narrative. At the central group, plot A, the wealthiest graves were defined by material culture and by their orientation. Aesthetically, these ancestors became central places within the cemetery and marked out this space, which defined both the adjacent burials and the people who used this plot. There were no children in plot A. The burials 


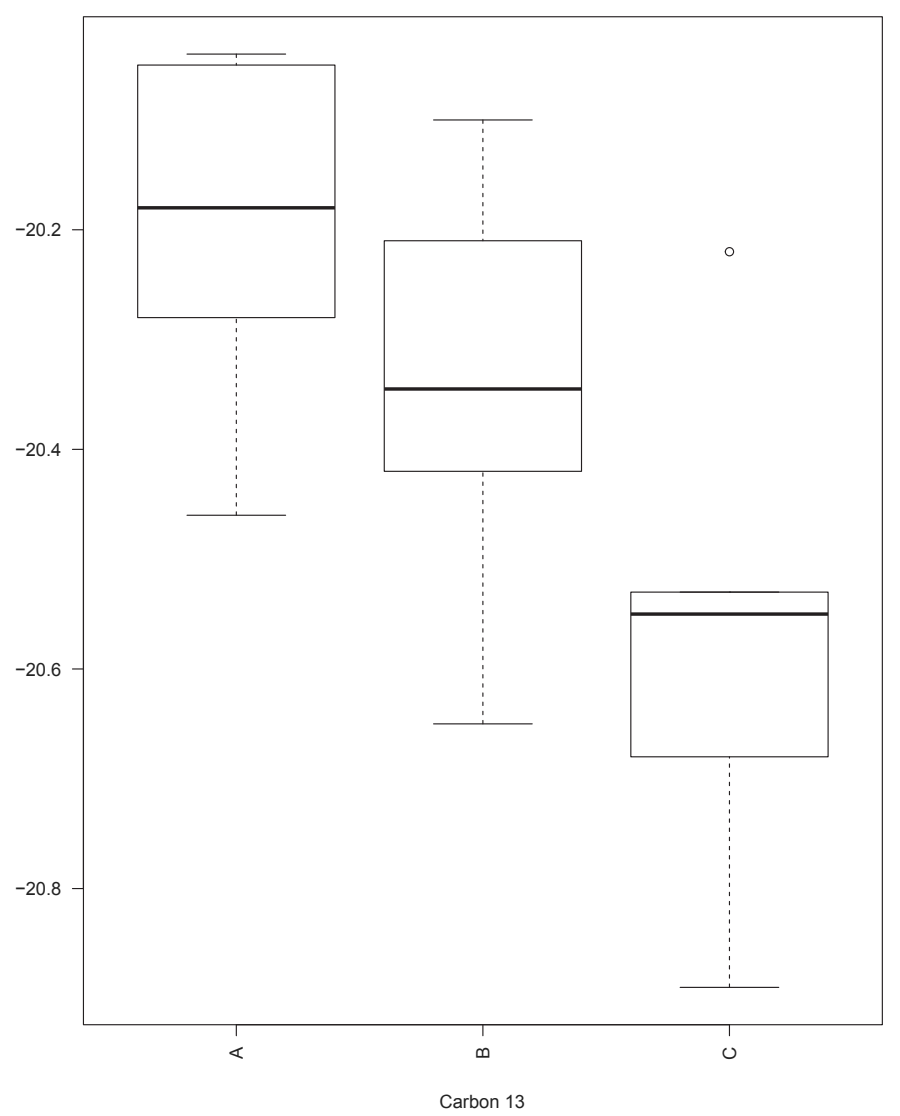

Figure 5.10 Worthy Park: adult carbon isotopes $\delta 13 \mathrm{C}$ box plots by burial area. The data from these three plots are statistically different; the distribution perhaps indicates that individuals in area $\mathrm{C}$ were more dependent on wild or woodland resources.

in plot D showed little evidence of internal structuring within their mortuary space, and additionally they had experienced a higher risk of trauma in their life. This community contained different lifeways, with different attitudes towards their antecedents and towards the expression of identity. Perhaps these people had different values and so expressed their identities differently within funerary places.

\section{Biological relatedness}

\section{Height}

Stature data are often recorded from skeletal material, but rarely used to explore social questions. Such data are central to the measurement of 
size, and they are also important because they are particularly sensitive to environmental conditions (Willey, 2009; Stinson, 2000). Adult stature has been used by health scientists as a measure of the welfare of modern populations (Steckel, 2006; 2009). Biocultural studies which use stature data derived from skeletal material explore hypotheses regarding health and nutrition in ancient societies, in particular how they varied with factors such as social status, subsistence strategy and living conditions (Larsen, 2015: 16-20; Mays, 2016). Heinrich Härke preferred to use stature to discuss ethnicity and described enclaves of British and AngloSaxon people which, he argued, showed greater divergence based on stature estimation measurements. He suggested that at Berinsfield there were two non-interbreeding populations with different biological heritages (Härke, 1990). Given that much of the literature on Anglo-Saxon archaeology focuses on ethnicity this is certainly thought-provoking, and must be considered carefully (see, for example, Thomas et al., 2006; Lucy, 2005; Hines, 1997; Härke, 2007). Equally, the small differences in height described, just a few millimetres, could certainly result from nutritional rather than ethnic differences (Tyrell, 2000). However, increasingly we are becoming aware that a large part of stature is determined by genetics, and it is interesting that archaeology often emphasises the environment and health aspects of stature, but does not explore how much variation is attributable to genetic effects, and how much is attributable to biological distance or relatedness (Lai, 2016). Recent genomic studies have tried to connect phenotypical and genetic variation statistically and they suggest that, accounting for nutritional environmental conditions, between 60 and 70 per cent of human height is the result of familial similarity rather than purely environmental factors (Yang et al., 2015: 8). Given this genetic link it might be possible to compare individual height data and discuss degrees of homogeneity or heterogeneity within biological populations. In this section I explore the biological similarities, or differences, that correspond to the mortuary technologies that have been described in previous chapters. As a result it is possible to suggest that the lifeways and attitudes described in the pathology section above can be understood as the results of different patterns of relatedness within the genders and also between groups of people that used the cemetery space in different ways. Due to the genetic component to height we might be able to observe different behaviours in cases where some cemeteries, or some groups within cemeteries, emphasised degrees of relatedness and used this to structure their mortuary space. The chronology and pathology sections of this book have suggested that there were generational burial patterns, that people returned to particular spaces for burial for generation after generation. It would be interesting, then, to explore whether these individuals shared similar statures. The adult human skeleton is 
not uniformly sexually dimorphic, and as a result males and females are considered separately (Humphrey, 1998).

To explore Härke's (1990) observations it is worth looking at Berinsfield in detail and then comparing it with a series of cemeteries where good-quality stature data have been taken according to Mildred Trotter's methodology (Trotter, 1970; Trotter and Gleser, 1952; 1958; 1977). At Berinsfield there were twenty-one adult male skeletons with height data available, and these ranged between $1.61 \mathrm{~m}$ to $1.85 \mathrm{~m}$. The average male at this cemetery was $1.73 \mathrm{~m}$. The individual in grave 117 was $1.85 \mathrm{~m}$ tall, which was $0.12 \mathrm{~m}$ more than the average. Of that $0.12 \mathrm{~m}, 60$ to 70 per cent was due to genetics; thus between $0.036 \mathrm{~m}$ and $0.048 \mathrm{~m}$ was likely to be due to environmental factors such as diet and lifestyle. As a result, it is unlikely that the tallest individual (in grave 117 and $1.85 \mathrm{~m}$ tall) and the shortest (grave 133/1, 1.61 m) were biologically related. The largest outside influence could have been environmental factors; for example, famine or malnutrition in childhood could have caused large differences between related individuals. However, the published report does not record any incidences of enamel hypoplasia, Harris lines or any other skeletal changes resultant from childhood malnutrition in a way that can be compared with the height data. As Härke (1990) has already observed, there were no discernible differences in the prevalence of enamel hypoplasia in terms of the health of males interred with or without weapons, which might imply that disease and malnutrition had been felt equally across the population.

Importantly, however, the variations in height data were distributed differently in weapon burials and non-weapon burials at Berinsfield (Figure 5.11). There were fifteen weapon burials with height data, and six non-weapon burials with height data available. Despite the larger number of weapon burials, they had the smaller range of distribution. The average height of a weapon burial was $1.73 \mathrm{~m}$, with the shortest $1.68 \mathrm{~m}$ and the tallest $1.78 \mathrm{~m}$. Each of these was just $0.05 \mathrm{~m}$ different from the average, and for each of them $0.035 \mathrm{~m}$ of this difference could be environmental. As a result, the difference between the tallest and shortest weapon burials suggested that these two might not be directly related, although more distantly related people have a larger degree of difference (Yang et al., 2015). It is noteworthy that these fifteen weapon burials' heights closely cluster together, with just a few centimetres separating them. And it is notable that the five weapon graves from plot $\mathrm{B}$ are much less diverse, with a range of just $0.07 \mathrm{~m}$ (between $1.71 \mathrm{~m}$ and $1.78 \mathrm{~m}$ ), meaning that these individuals were the most biologically homogeneous group in the cemetery (Figure 5.12). By contrast, the non-weapon burials also had an average of $1.73 \mathrm{~m}$, but a range of $0.24 \mathrm{~m}$, from $1.85 \mathrm{~m}$ to $1.61 \mathrm{~m}$, meaning a higher degree of biological diversity within this subgroup of the population. 


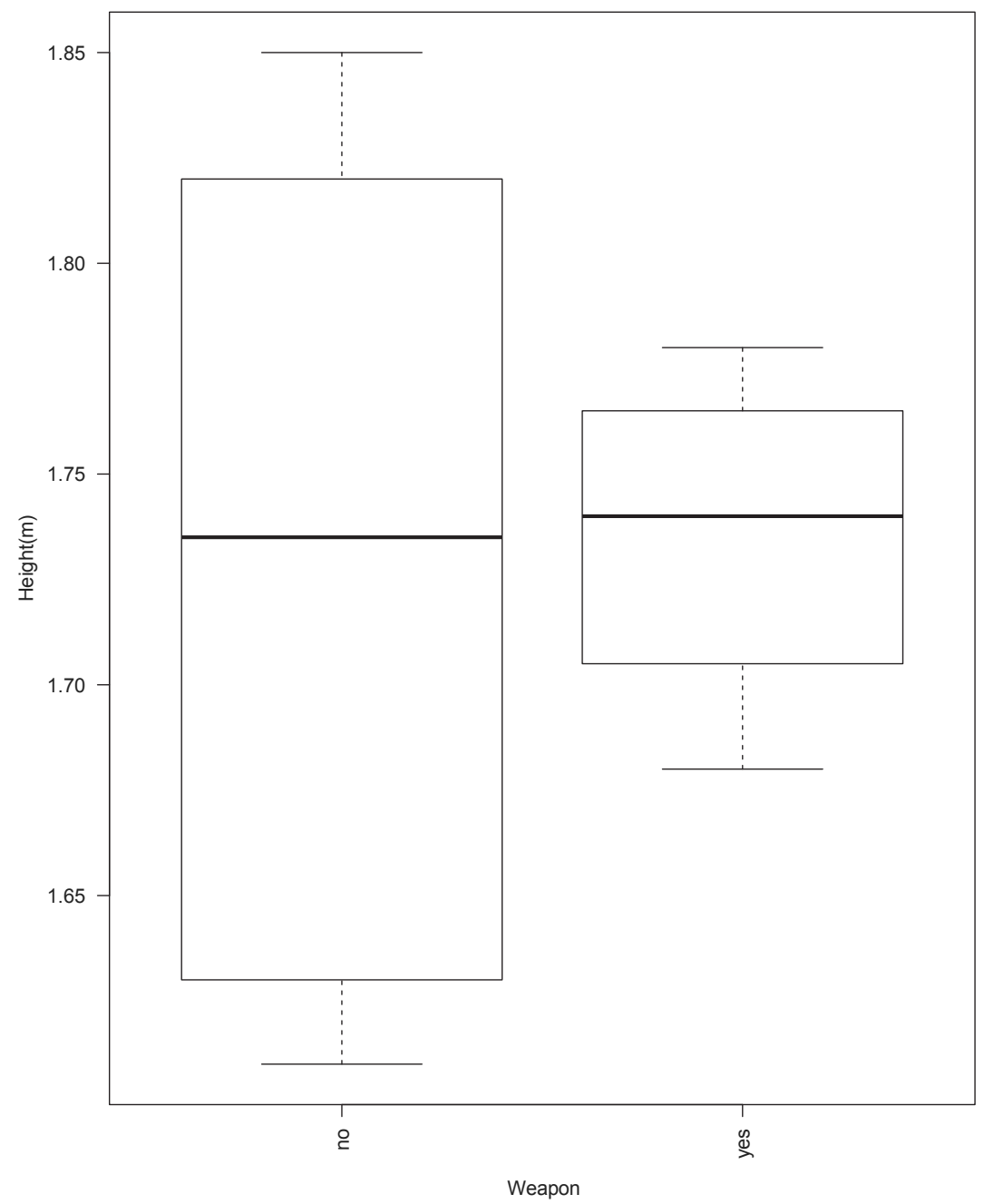

Figure 5.11 Berinsfield: height data differences between weapon and non-weapon burials. This shows that the weapons burials had the smaller range of distribution. The average height of a weapon burial was $1.73 \mathrm{~m}$, with the shortest $1.68 \mathrm{~m}$ and the tallest $1.78 \mathrm{~m}$.

The female population of Berinsfield does not seem to have had the same character as that of the male (Figure 5.13). There were sixteen brooch burials among this population, and these showed a greater degree of heterogeneity than there was among the women without brooches (Figure 5.14). The most similar in height were those women without brooches; on average these were shorter than those with brooches and had an average height of $1.60 \mathrm{~m}$, contrasting with $1.63 \mathrm{~m}$ 


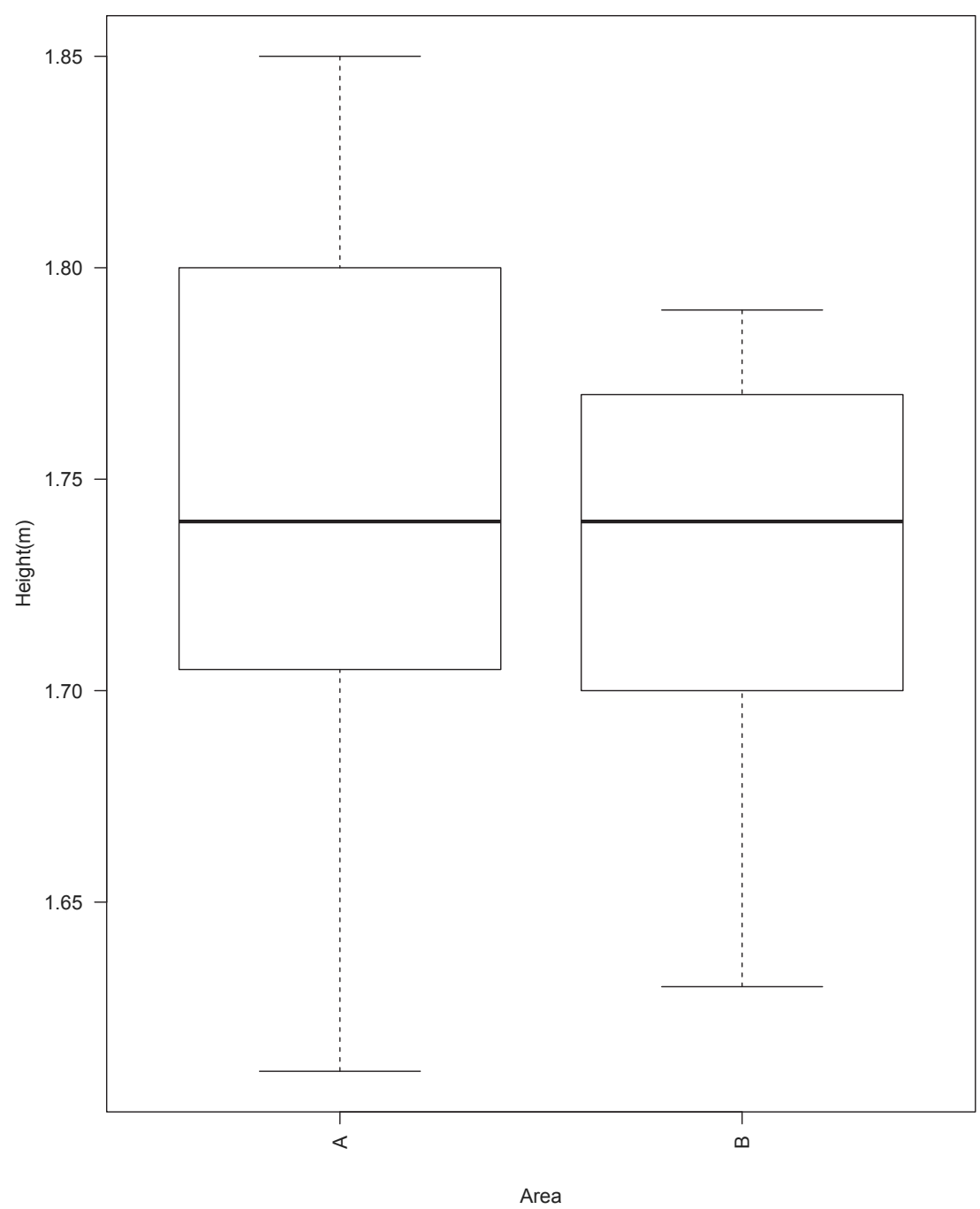

Figure 5.12 Berinsfield: height data differences between weapon burials in plots A and $\mathrm{B}$. The area $\mathrm{B}$ weapon burials were less diverse than area $\mathrm{A}$ burials.

for those with brooches. The non-brooch burials were eight inhumations between $1.52 \mathrm{~m}$ and $1.68 \mathrm{~m}$ tall, a range of $0.16 \mathrm{~m}$, but most clustered between $1.58 \mathrm{~m}$ and $1.63 \mathrm{~m}$. This variation suggested that these women were diverse, but it is possible that some of these women had a degree of biological relatedness among the non-brooch burials. The brooch burials had a greater degree of heterogeneity, with a range from $1.55 \mathrm{~m}$ to $1.72 \mathrm{~m}$, with most being found between $1.59 \mathrm{~m}$ and $1.68 \mathrm{~m}$, a wide range suggesting that the use of brooches was not connected to 


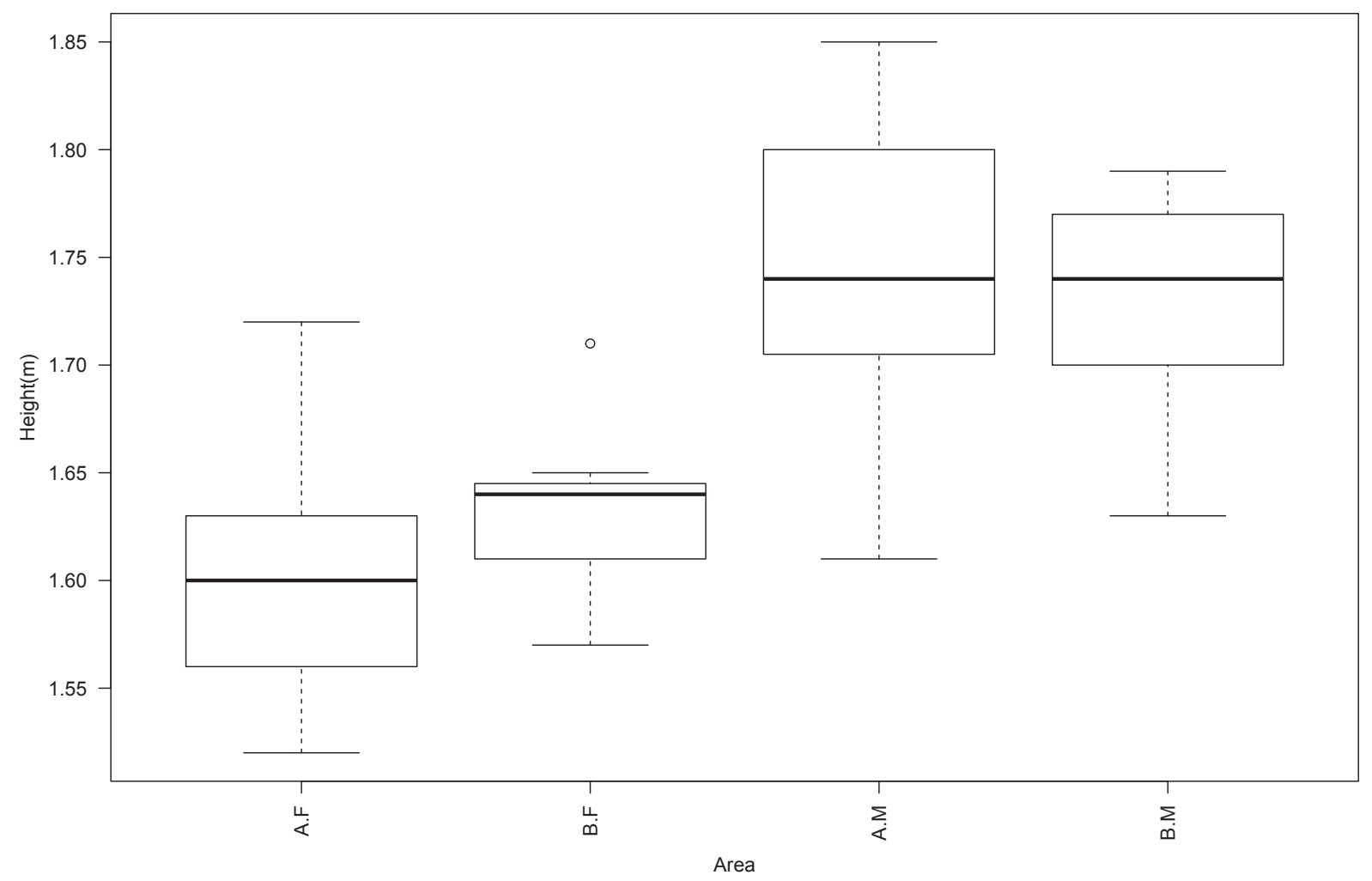

Figure 5.13 Berinsfield: height data by gender. Females in plot B had the narrowest range, and the two female groups had very different height distributions. Males, by contrast, showed a very similar height distribution when comparing these two plots. 


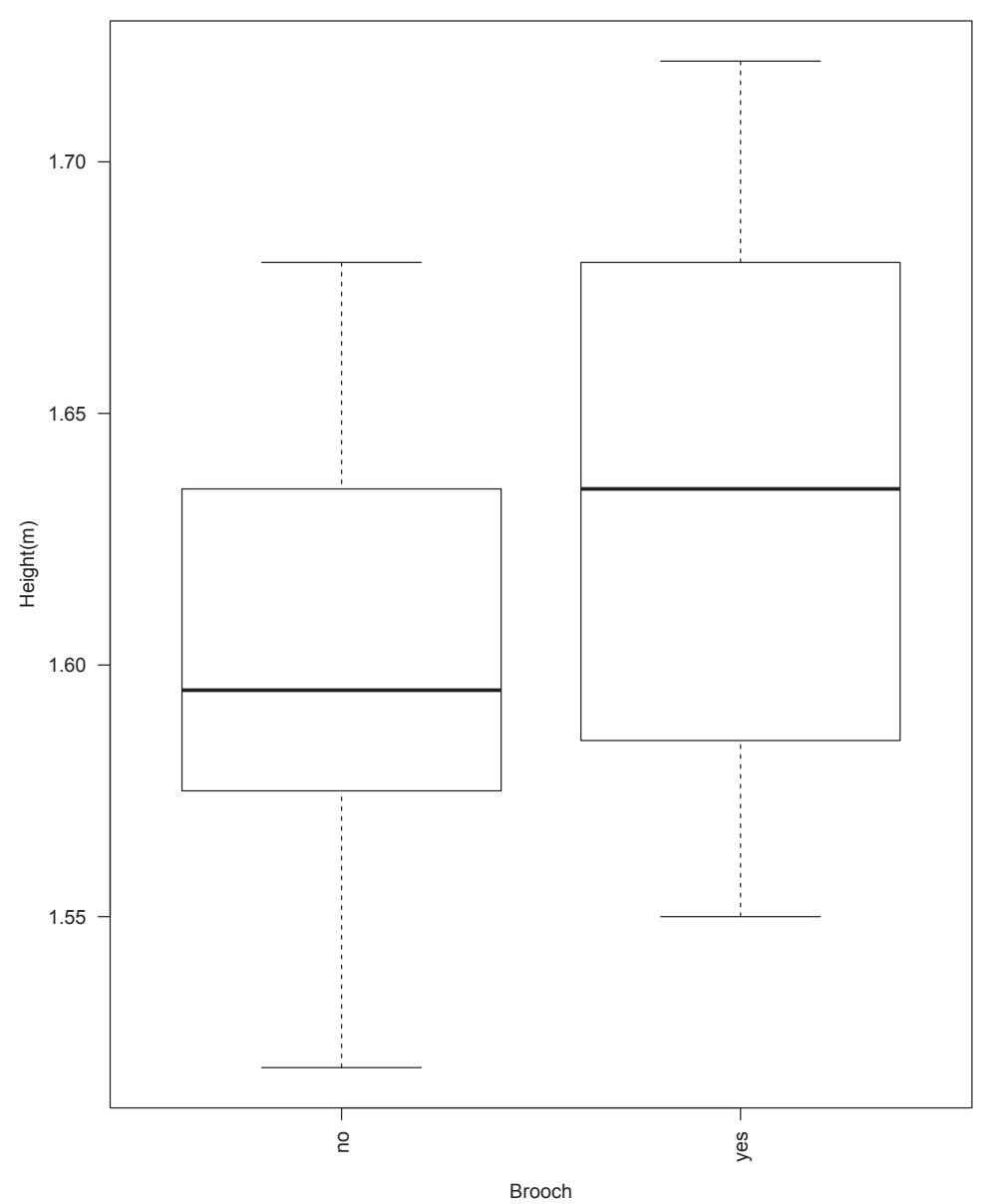

Figure 5.14 Berinsfield: height data with and without brooches. There was more similarity in height among burials of females without brooches than among burials with brooches.

biological relatedness in the same way that it may have been for some weapon graves at this site.

When these same data are expressed by biological sex and spatial grouping, there are some interesting, and contrasting, patterns evident (Figure 5.15). For example, the women in plot B with brooches had the narrowest range, with a concentration between $1.61 \mathrm{~m}$ and $1.65 \mathrm{~m}$, and a particular cluster around the top of this range. Graves $77(1.65 \mathrm{~m})$ and $73(1.63 \mathrm{~m})$, as well as 25 and 54 (both $1.64 \mathrm{~m}$ ), were all within $1 \mathrm{~cm}$ of the plot's average height and were the most homogeneous female burials. These graves had a variety of different material cultures within them. Notably, the two female plots had very different height 


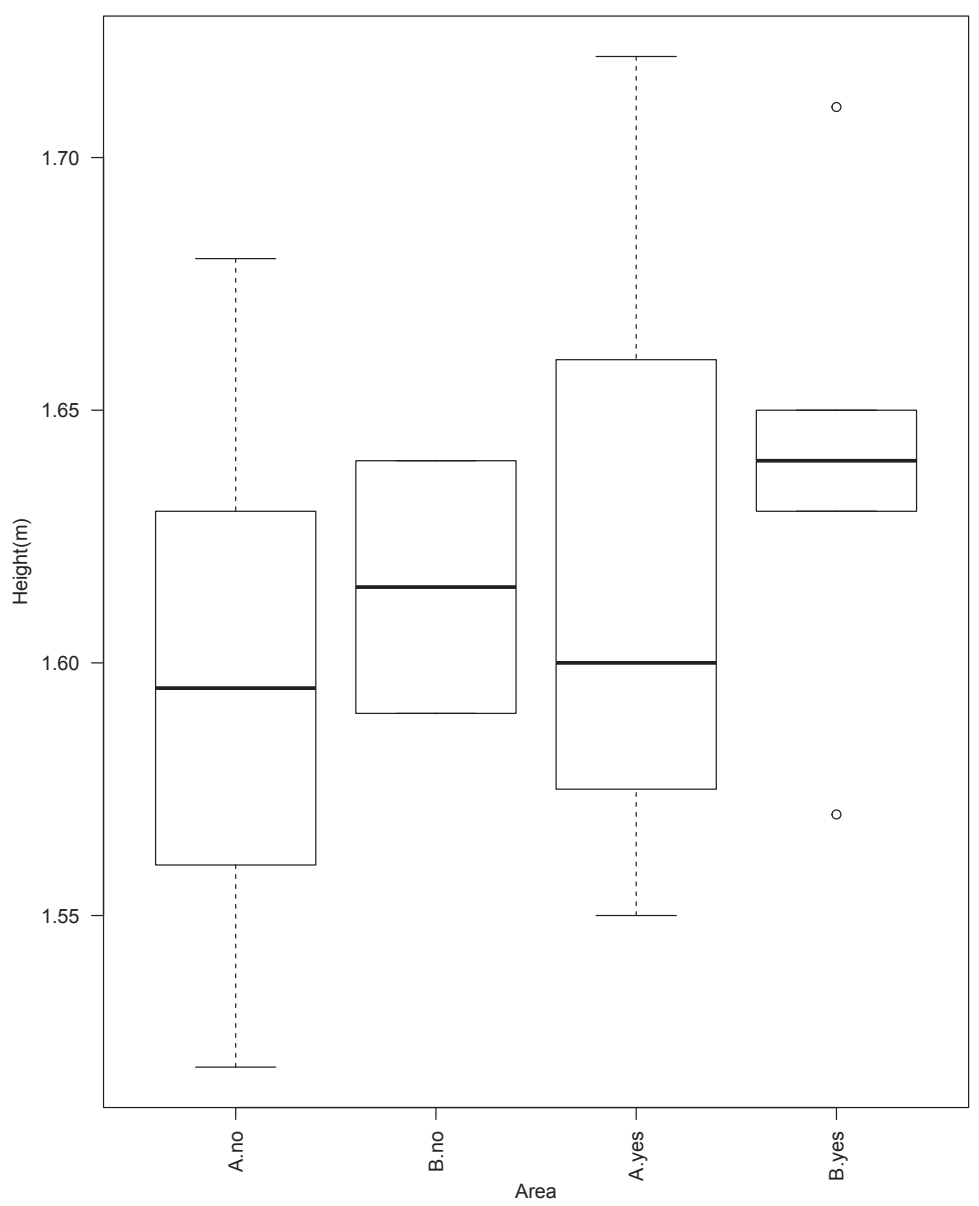

Figure 5.15 Berinsfield: height data by plot, with and without brooches. The burials most similar in height were those of females in Plot B without brooches.

distributions and averages, suggesting a high degree of heterogeneity among these groups. The men, by contrast, showed a range of heights, with the same average figure for both plots, which suggests there was some homogeneity within this population; this degree of cross-plot comparison is probably the result of the similarity between the male weapon burials that we witnessed earlier.

By contrast, the cemetery at Great Chesterford showed greater homogeneity within the female population, with a wide quartile but similar average heights in all four burial areas, suggesting some degree of internal similarity across the female population (Figure 5.16). In comparison the male population was much more diverse, with huge variations within and between burial areas (Figure 5.17). Interestingly, 


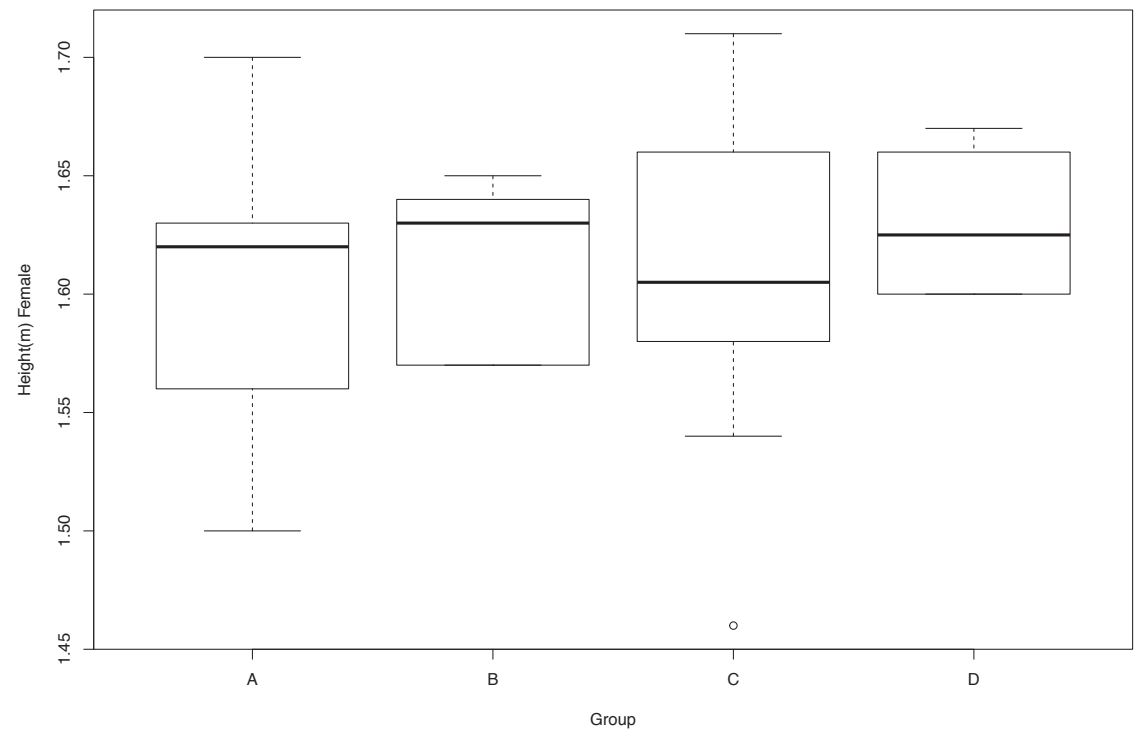

Figure 5.16 Great Chesterford, Essex: female height. With a wide interquartile range, but similar average heights in all four burial areas, there may have been some degree of similarity within the female population. Compare this with Figure 5.18, which shows no such similarity among the males.

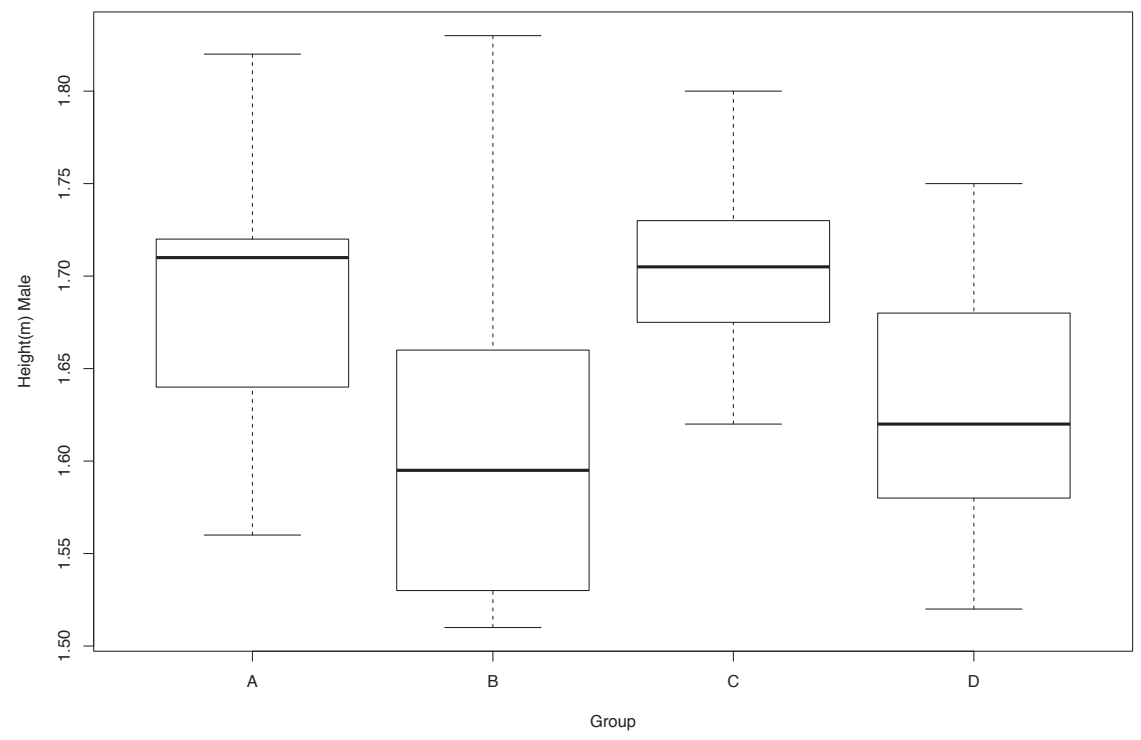

Figure 5.17 Great Chesterford: male height. In contrast to the female heights shown in Figure 5.16, the male heights were very diverse and showed much less similarity between the burial plots. 


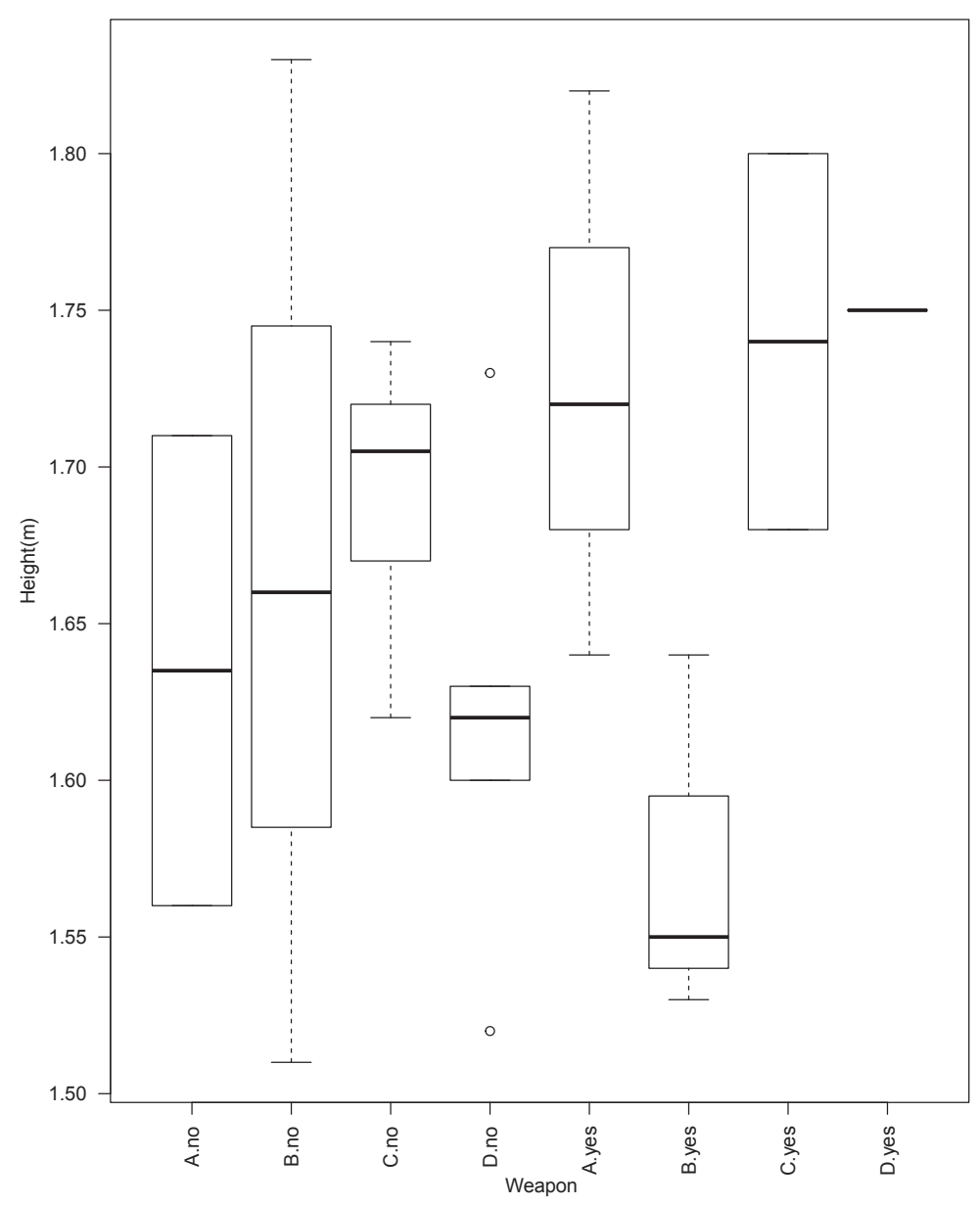

Figure 5.18 Great Chesterford: comparison of the height of men with weapon and non-weapon burials from each plot. The most closely comparable groups of males with weapons were in plots A and C. Weapons burials from area B were the most homogeneous.

the most similar males were those found in areas A and C, with comparable average figures. This degree of similarity was also seen in the distributions of height and weapon burials, where the most similar were men with weapons in A and C, but the greatest degree of homogeneity was present among males with weapons from area B, who were comparatively short (Figure 5.18). The greatest degree of heterogeneity existed within the non-weapon burials. It is not possible to see any patterns within the female data related to the presence or absence of brooches, which suggests that female identity was not expressed using 


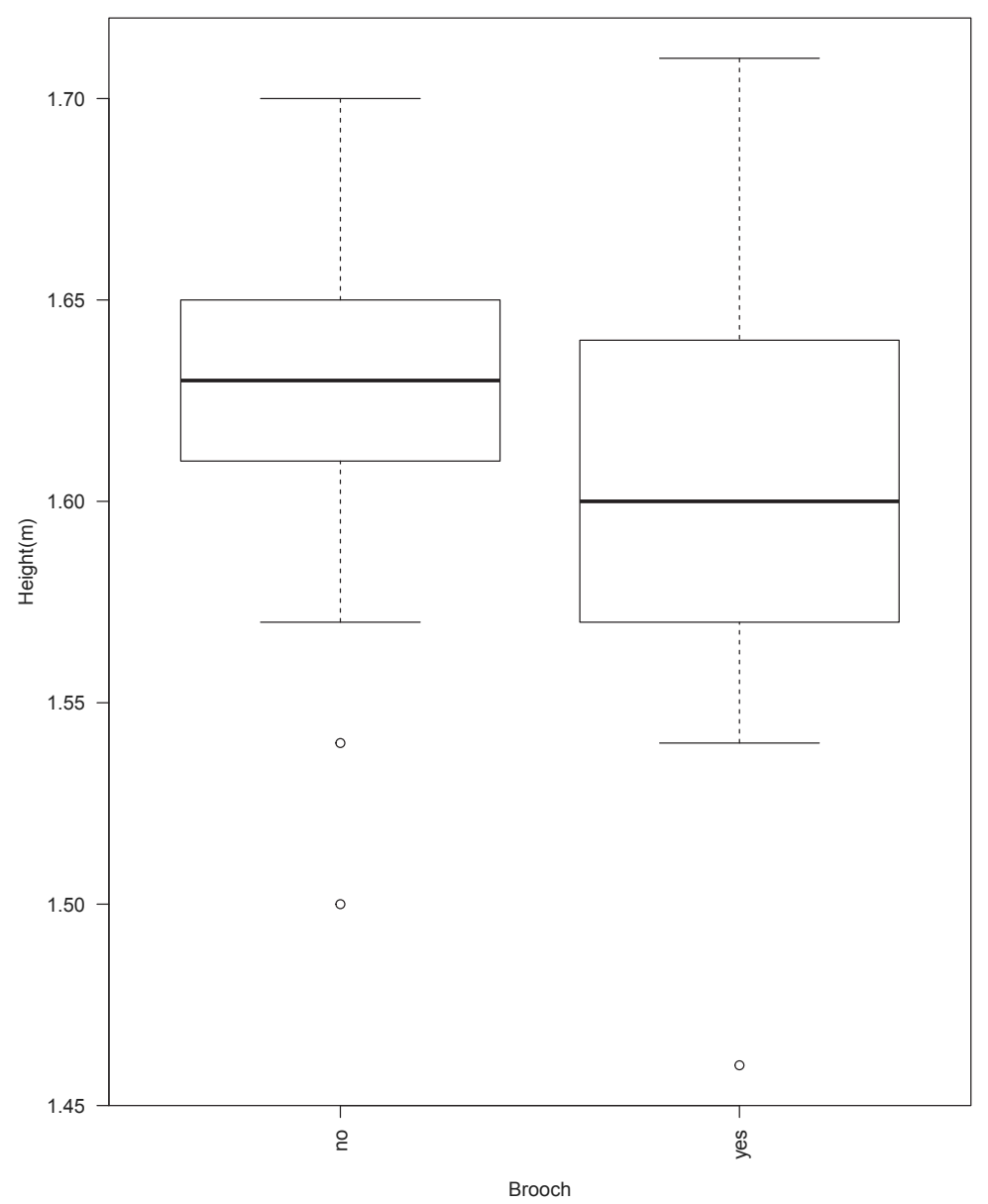

Figure 5.19 Great Chesterford: comparison of the height of women with brooch and non-brooch burials. The heights of brooch burials varied by over $10 \mathrm{~cm}$.

material culture in the same way as it was among the male burials. In a similar way to Berinsfield, at Great Chesterford there was a greater degree of homogeneity within the female population that did not dress with brooches; the majority of these individuals were situated within a $0.04 \mathrm{~m}$ height range, a more homogeneous group which probably included many related individuals (Figure 5.19). The brooch burials, however, had a range of over $0.10 \mathrm{~m}$ suggesting that they were heterogeneous, and so had different and diverse biological heritages.

Apple Down is also very interesting. Men with weapons in configuration A burials were, on average, taller than men with weapons in configuration B burials (Figure 5.20). They were also taller than the men without weapons within both configurations. Men without weapons had a much 


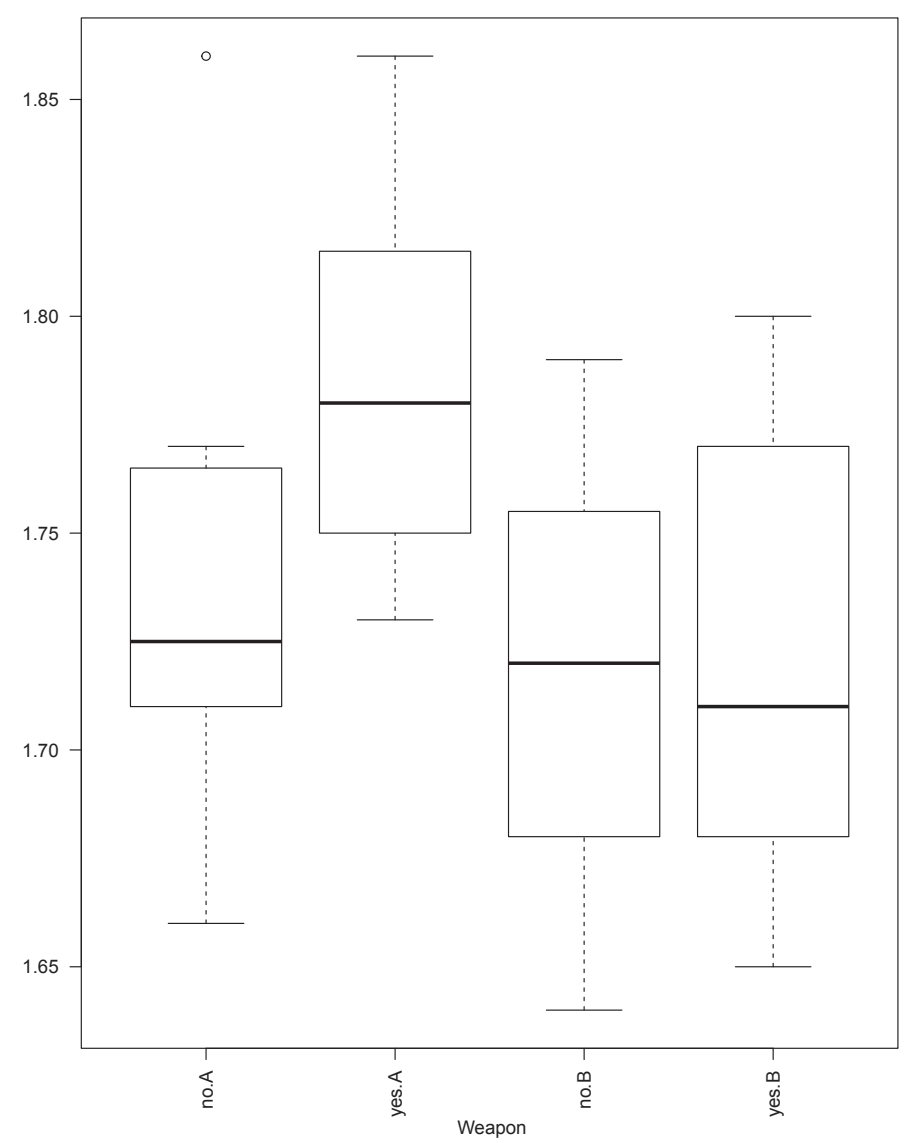

Figure 5.20 Apple Down, Kent: weapon burials by height. Males with weapons in configuration A burials were, on average, taller than males with weapons in configuration B burials and males without weapons.

greater range of heights, which varied over $0.15 \mathrm{~m}$ between the tallest and the shortest individuals, and the range was very similar among the different styles of burial. This pattern is most striking in the male weapon burials, but it was also evident in the gender difference according to burial configurations (Figure 5.21). The males from the configuration A graves were a few centimetres taller on average than those from configuration $\mathrm{B}$, regardless of material weapons. Interestingly, the average height of women in groups A and B was very similar, but notably there seems to have been a much greater degree of similarity between the females in the configuration B burials, with most just $0.05 \mathrm{~m}$ in difference, as opposed to those in configuration $\mathrm{A}$ with around $0.10 \mathrm{~m}$ between them. Configuration A females had a total range of $0.18 \mathrm{~m}$ between the tallest and the shortest. 


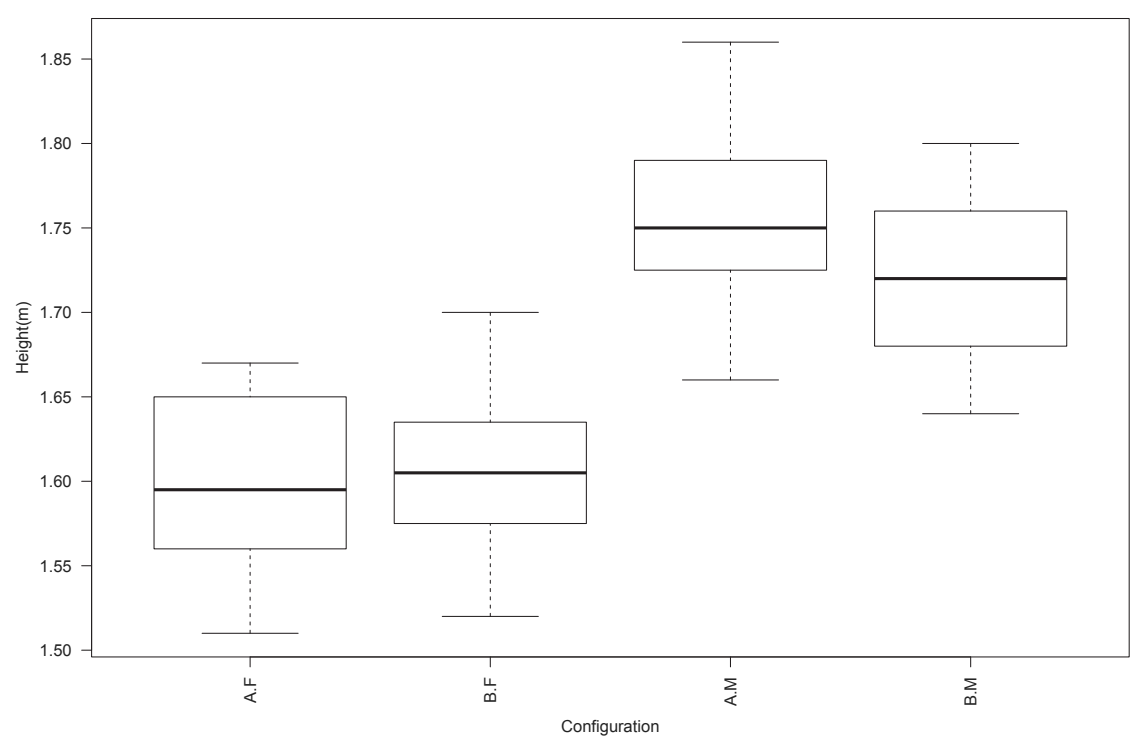

Figure 5.21 Apple Down: height box plot by gender. Males from A graves were a few centimetres taller on average than those from configuration B graves. By contrast, the average height of females in A and B graves was very similar.

This pattern suggests that were differences between the configurations in the homogeneity of males and females. The women were most similar across the whole populations but, significantly, the male weapon burials of configuration A showed the greatest degree of homogeneity, as they did in the burial areas at Berinsfield and Great Chesterford.

Worthy Park had a similar pattern to the male weapon burials. Like Apple Down, Worthy Park had a very masculine feel to the material culture (see Chapter 4); for example, there were just four brooch burials but nineteen male weapon burials. As with Apple Down, there was a pattern within the weapon burials, but it was specific to a particular group. Worthy Park had two burial zones evident in the biological data, A and B. Area A was to the south and had the greatest density; it was characterised by burials of different orientation and had a significant number of intercutting graves. Area B, to the north, was less dense (Figure 5.22). The height data in each area were interesting, and the area $\mathrm{A}$ females had the tightest range. These women fitted between $1.50 \mathrm{~m}$ and $1.68 \mathrm{~m}$ tall, but most were between $1.58 \mathrm{~m}$ and $1.64 \mathrm{~m}$, illustrated by the box plot (Figure 5.23). By contrast, the females from area B were wide-ranging between $1.52 \mathrm{~m}$ and $1.73 \mathrm{~m}$. The men were similar to those in area A and slightly taller on average. When explored by orientation, both sexes showed diversity, most evident among the E/W oriented female graves 


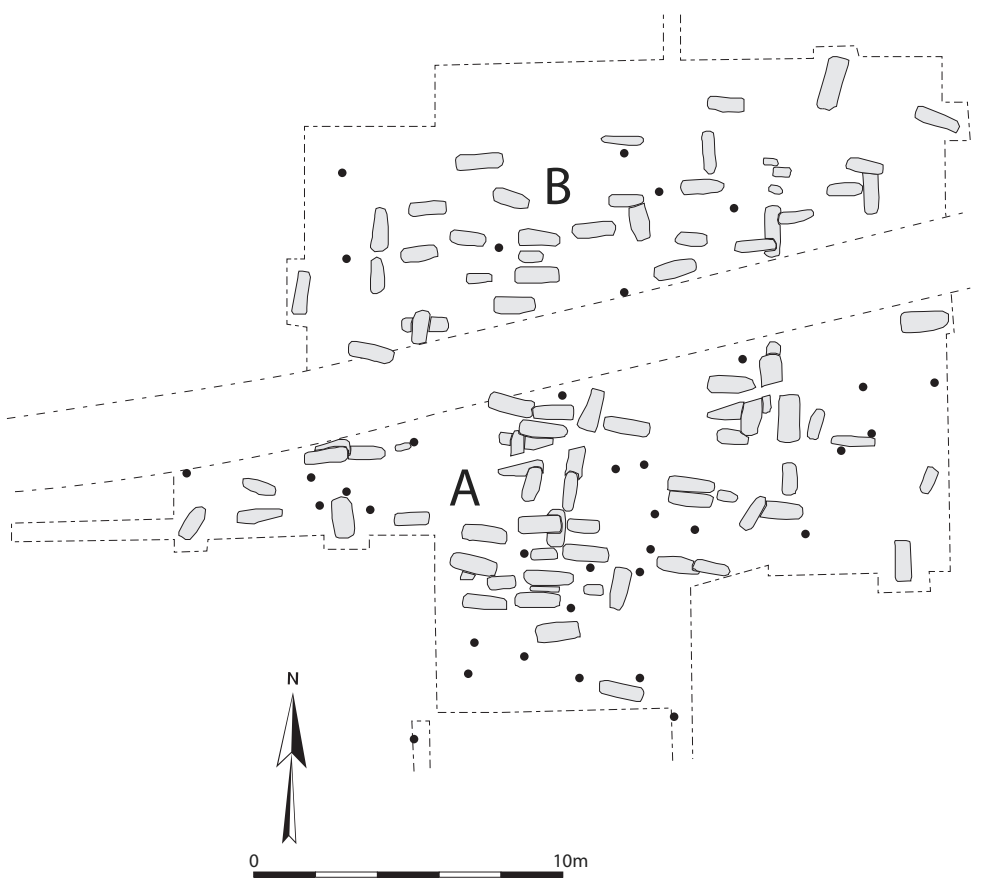

Figure 5.22 Worthy Park, Hampshire: plan to illustrate the layout of the cemetery.

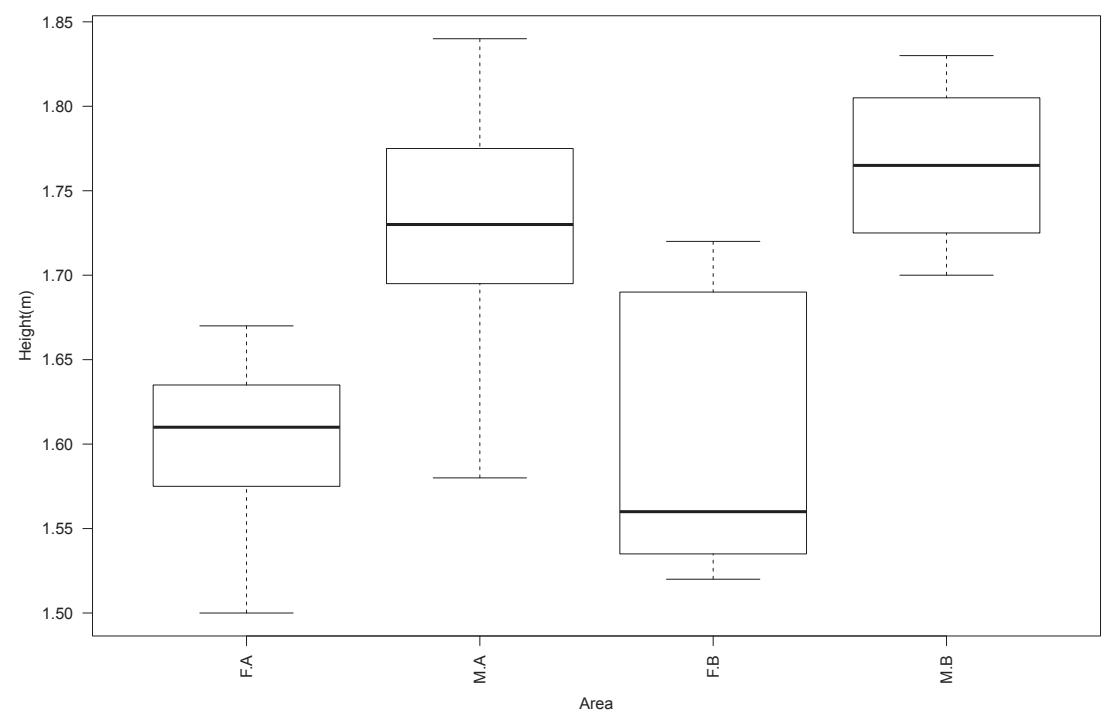

Figure 5.23 Worthy Park: height and biological sex by area. $\mathrm{F}=$ female, $\mathrm{M}=$ male. Plot A had the most structure to it, but the female graves in plot B showed the greatest diversity in terms of height. 


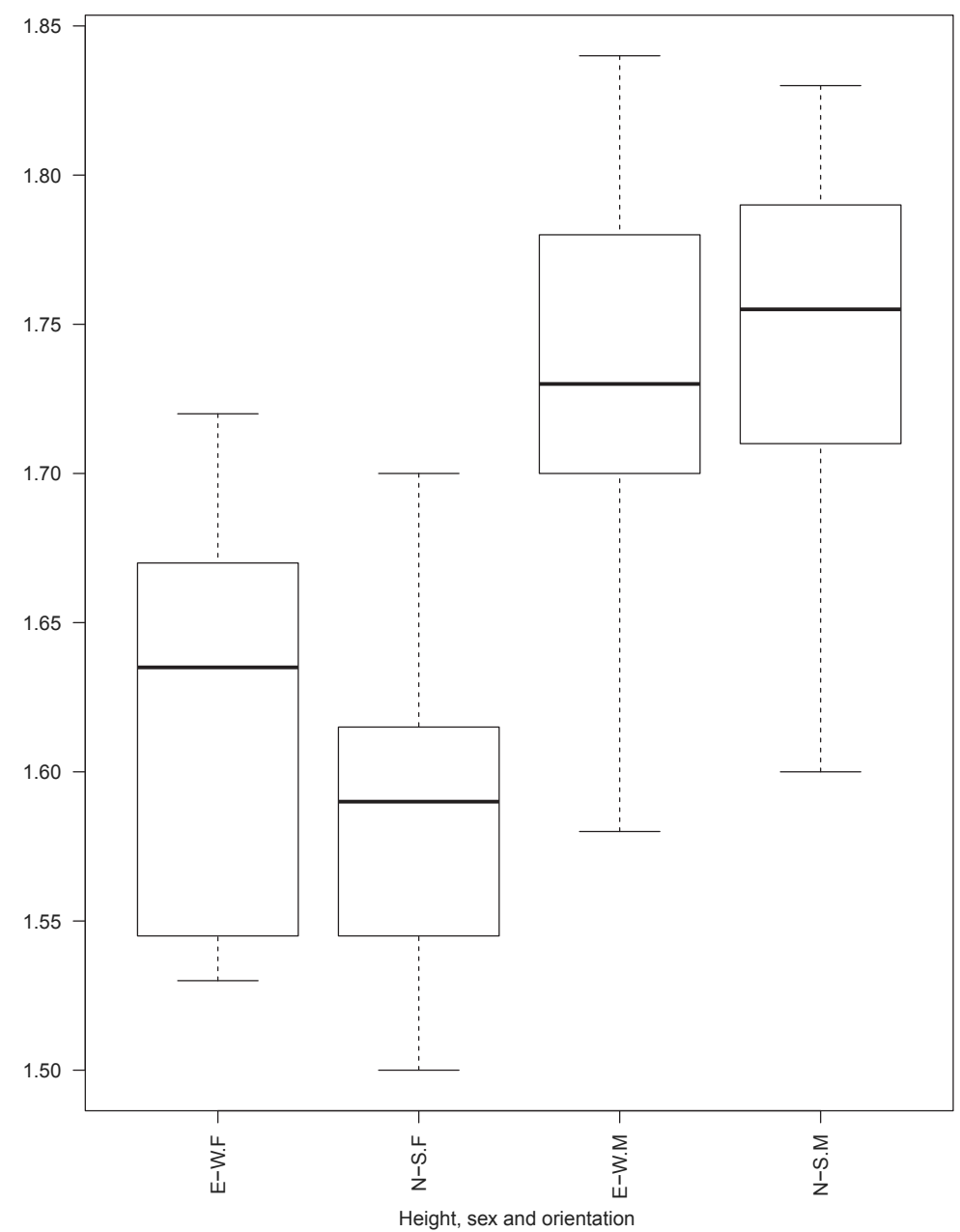

Figure 5.24 Worthy Park: height data by gender and grave orientation. Both sexes showed diversity, with the greatest range evident among the E/W-oriented females.

(Figure 5.24). Male burials were broadly similar based on orientation alone. However, when the male graves were explored by looking at the presence or absence of a weapon, the picture changed dramatically (Figure 5.25). Plot A had the most structure to it, and these males were oriented in different ways, but the graves without weapons showed the greatest diversity in terms of height, which ranged between $1.60 \mathrm{~m}$ and $1.80 \mathrm{~m}$. The $\mathrm{E} / \mathrm{W}$ oriented weapon graves were the tightest group, despite being one of the largest collections of burials, with five graves: nos. 22 $(1.72 \mathrm{~m}), 45(1.73 \mathrm{~m}), 46(1.69 \mathrm{~m}), 95(1.75 \mathrm{~m})$ and 44 , which was an outlier at $1.84 \mathrm{~m}$ (or six foot!). The E/W weapon graves in plot A were 


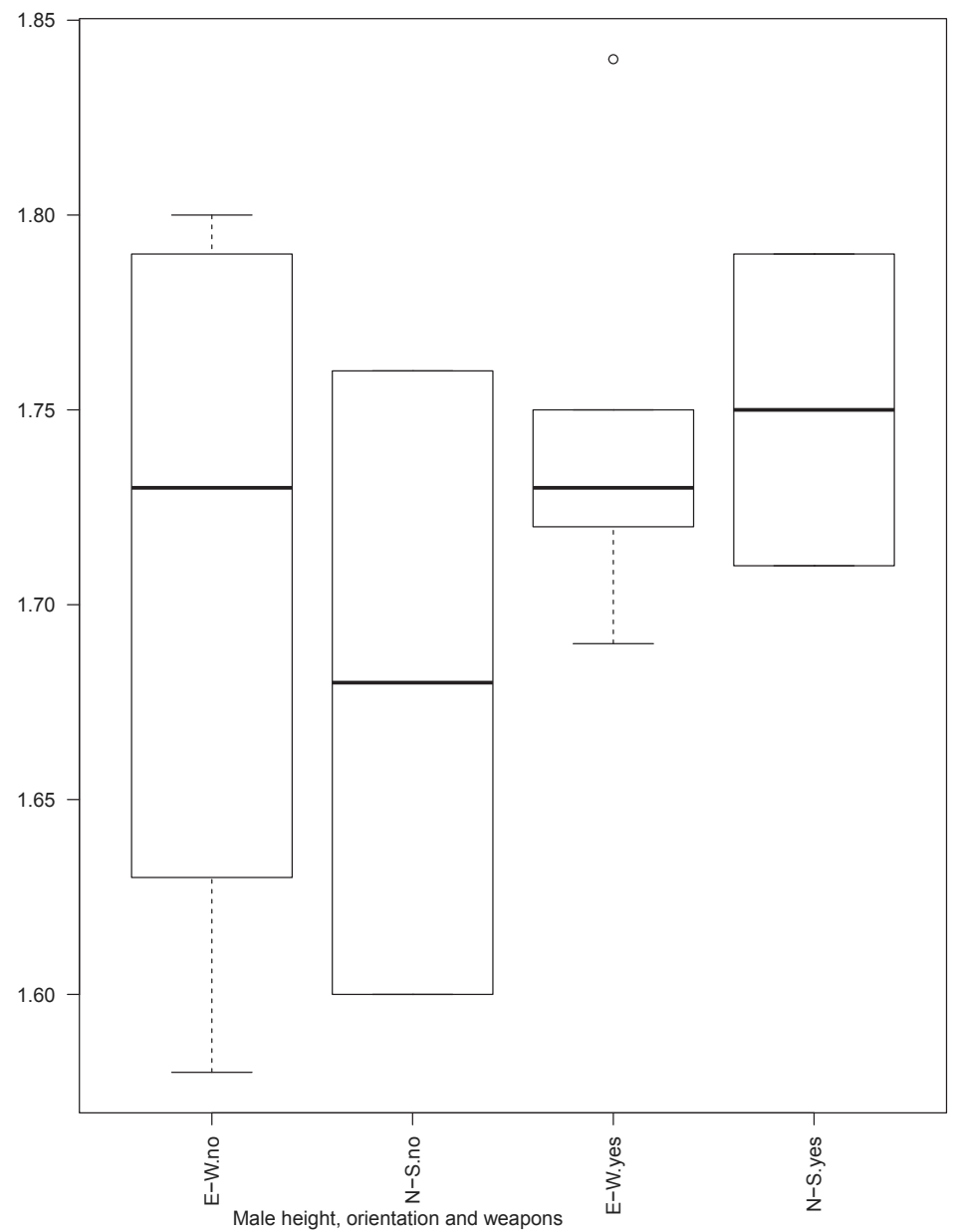

Figure 5.25 Worthy Park: height and weapons by grave orientation in burial area A. The E/W-oriented weapon graves were the most closely related group in the cemetery.

the most homogeneous group in the cemetery, a result which may suggest some degree of biological similarity between them.

At Lechlade, there were five groups of burials, A to E, with A and B separated by a Bronze Age barrow. Group C was a cluster to the east, $\mathrm{D}$ was a group of burials partly organised around a row of graves and $\mathrm{E}$ was the later phase distributed across the cemetery; many phase $\mathrm{E}$ burials were on an E/W orientation at odds with the earlier graves (see Figure 6.9). Notably, each of these burial groups included a range of male and female heights (Figure 5.26). Among the burials in groups A, $\mathrm{B}, \mathrm{C}$ and $\mathrm{E}$ the males had a much greater distribution, with the males 


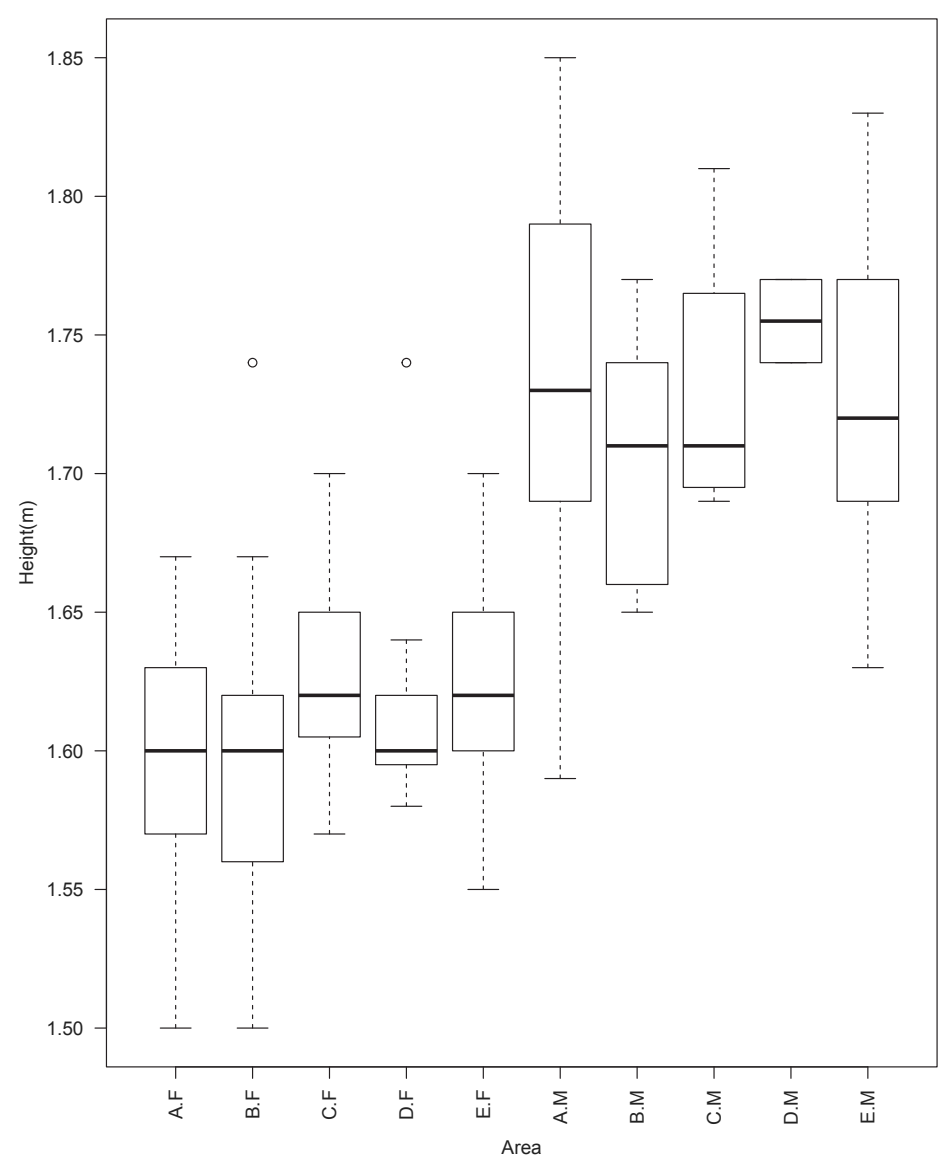

Figure 5.26 Lechlade, Gloucestershire: height by plot and gender. Males in plots $\mathrm{A}, \mathrm{B}, \mathrm{C}$ and $\mathrm{E}$ had a large range, females in $\mathrm{D}$ the tightest range and in groups $\mathrm{A}$, $\mathrm{B}, \mathrm{C}$ and $\mathrm{E}$ the interquartile range of heights among the females was much smaller than among the males. Plot D contained a small number of males.

from group A varying over $20 \mathrm{~cm}$ in height. This height difference suggests these males were a heterogeneous group. The females had a much tighter range, and in groups $\mathrm{A}, \mathrm{B}, \mathrm{C}$ and $\mathrm{E}$ the interquartile range varied up to $5 \mathrm{~cm}(\mathrm{C}$ and $\mathrm{E})$ and $6 \mathrm{~cm}(\mathrm{~A}$ and $\mathrm{B})$ in height. Group D was interesting and consisted of a small group of burials focused around a row. There were only two males with height data, and both were weapon burials: graves $35(1.77 \mathrm{~m})$ and $92(1.74 \mathrm{~m})$. However, there were seven females with height data available, and five of these were within $3 \mathrm{~cm}$ of each other: burials 18 (1.6 m), 81/1 (1.6 m), 81/4 (1.6 m), 165 $(1.59 \mathrm{~m})$ and $167 / 2(1.58 \mathrm{~m})$. This was a tight enough cluster of heights that this difference could easily be understood as being the product of 


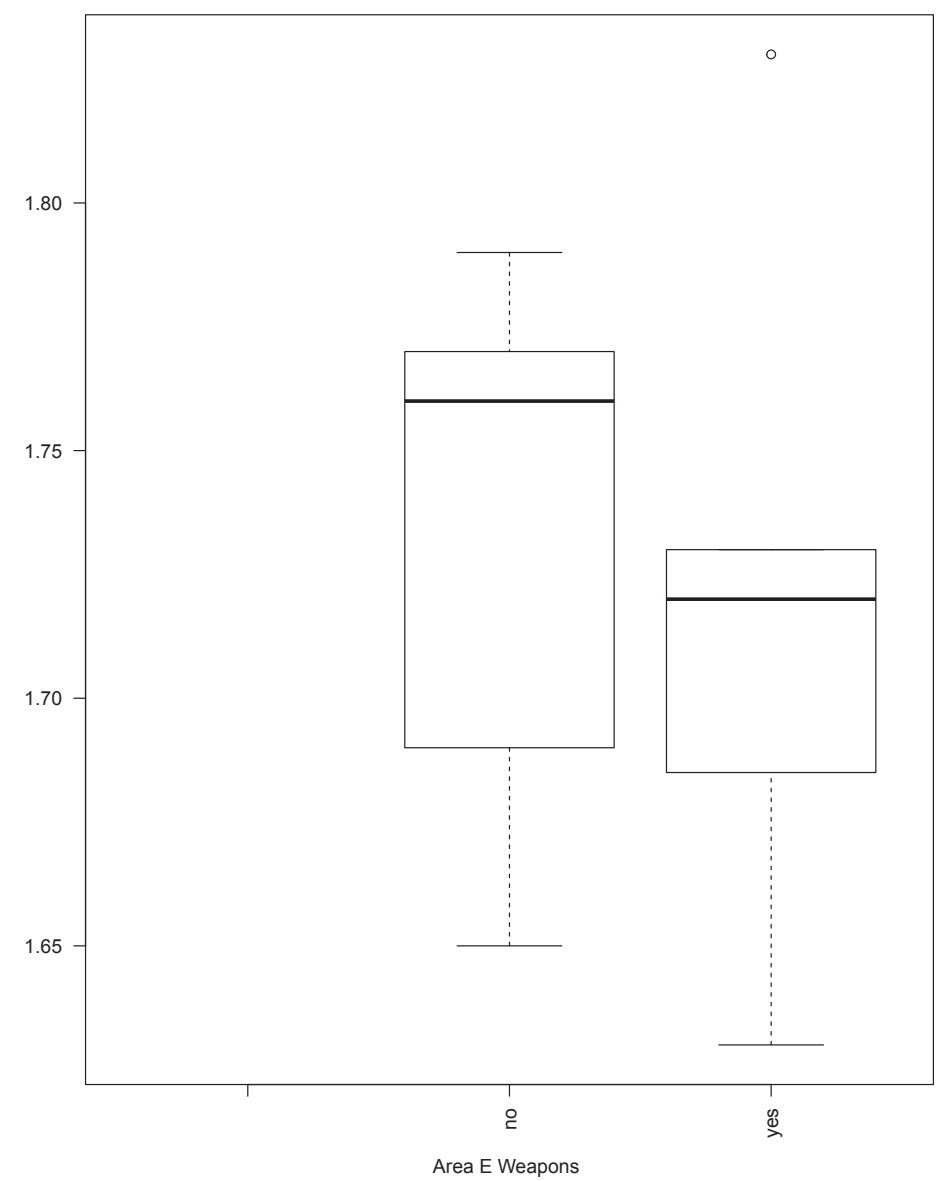

Figure 5.27 Lechlade: weapon burials in seventh-century burial area E. The male weapon burials of this configuration were more homogeneous than the nonweapon graves.

environmental variation. In short, these women were homogeneous and there is a very good chance they were related.

The final-phase burials at Lechlade included group E, which was a very diverse range of inhumations spread across the main burial area, and across a new burial area to the south of the cemetery. Notably, the male weapon burials of this configuration were in the north of the cemetery and were much more homogeneous in nature than the non-weapon graves (Figure 5.27). Certainly, the five weapon graves $-40(1.72 \mathrm{~m})$, $104(1.72 \mathrm{~m}), 155(1.73 \mathrm{~m}), 172 / 3(1.73 \mathrm{~m})$ and $181(1.72 \mathrm{~m})-$ all had men within $1 \mathrm{~cm}$ of each other in height. There were three outliers graves 106 and 178 (1.63 $\mathrm{m}$ and $1.65 \mathrm{~m}$ respectively) and 121, who was 
very tall at $1.83 \mathrm{~m}$. Although not a completely homogeneous group, it is evident that there was a core community of later-sixth-century and early seventh-century weapon graves at Lechlade with extraordinarily similar heights, indicating that they were almost certainly related. Indeed, across the whole date range, the weapon burials were much more homogeneous than the non-weapon burials; the interquartile range of weapon graves ranged between $1.70 \mathrm{~m}$ and $1.74 \mathrm{~m}$, with an average of $1.72 \mathrm{~m}$. The interquartile group of non-weapon graves ranged between $1.69 \mathrm{~m}$ and $1.77 \mathrm{~m}$ and had an average height of $1.72 \mathrm{~m}$, meaning that although there were similarities between these groups there was a very strong homogeneous component to the male weapon graves at Lechlade.

By way of contrast, this pattern was not seen among the brooch burials (Figure 5.28). The quartile for non-brooch graves varied between

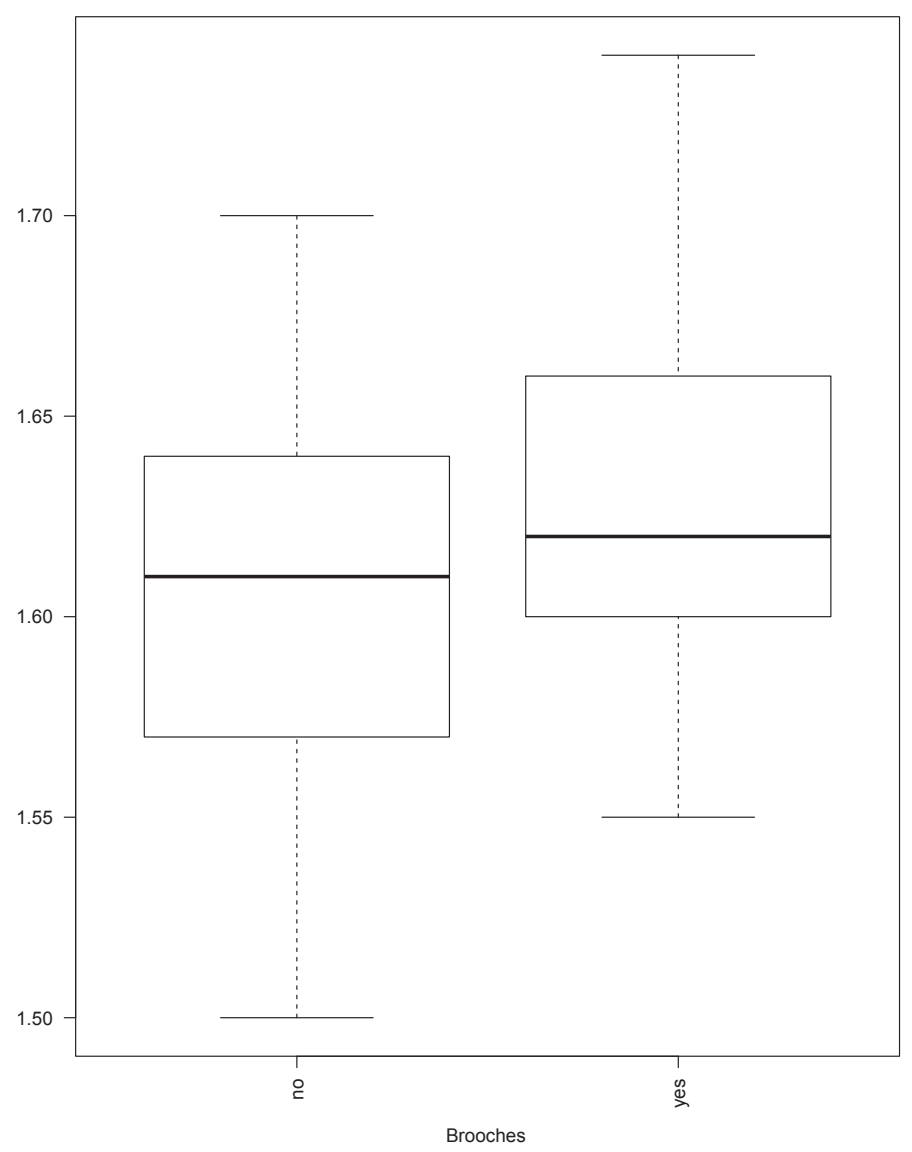

Figure 5.28 Lechlade: height and brooch burials. The brooch and non-brooch burials had a similar degree of heterogeneity. 
$1.57 \mathrm{~m}$ and $1.64 \mathrm{~m}$ and the interquartile group of brooch burials ranged between $1.59 \mathrm{~m}$ and $1.66 \mathrm{~m}$. Both brooch and non-brooch burials had a similar degree of heterogeneity. In particular, among the twenty-five women in area $\mathrm{E}$ there was a much greater degree of difference between the two brooch burials, graves $127(1.56 \mathrm{~m})$ and $164(1.55 \mathrm{~m})$, than between the non-brooch burials, which had an interquartile cluster between $1.61 \mathrm{~m}$ and $1.65 \mathrm{~m}$ (Figure 5.29). This pattern was also seen across the other cemeteries discussed in this chapter, and as a result it is very unlikely that brooch burial was used as a way of distinguishing women who belonged biologically to a particular family, whereas weapon burials appear to have had a high degree of homogeneity.

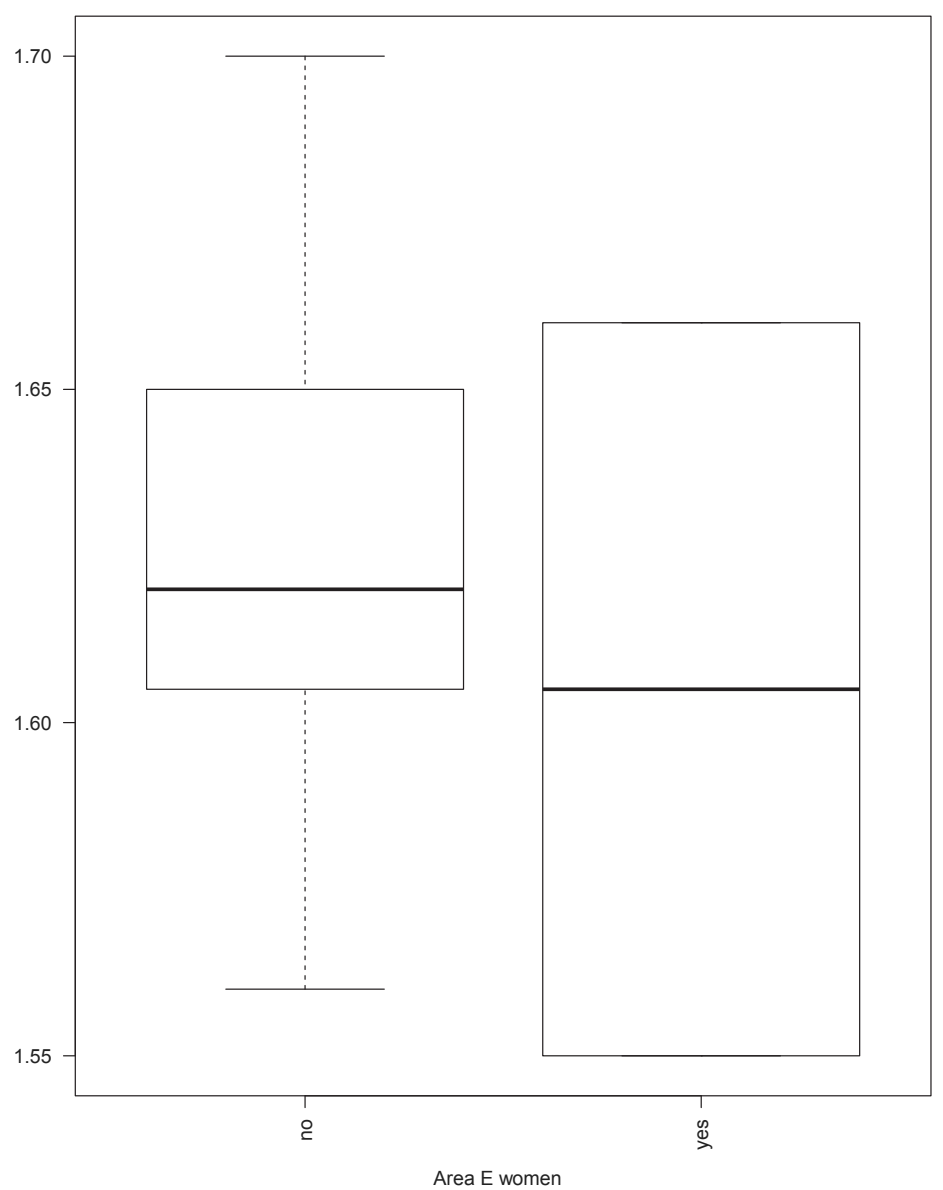

Figure 5.29 Lechlade: height and brooch burials in the seventh-century area E. There was a much greater degree of difference between the two brooch burials than among the twenty-five burials without brooches. 
Weapon graves may thus have been afforded to male members of particular familial groups, although there is certainly enough variation within the cemetery data discussed here to suggest this was not the only reason men were interred with weapons.

The importance of height data in examining the health of past populations is undeniable (Mays, 2016), as is the impact of the environment on population height. Even more influential, however, are the underlying genetics. When fully grown, the range into which a person's height will fall is determined by their parents. Inevitably, their final height will be determined both by the environment and genetics together, but the impact of the environment upon this is limited. Obviously, a particular individual will be most similar to their siblings and their parents when compared against more distant relatives, and more different still to unrelated individuals. In the examples discussed here there were evident patterns in the distribution of height data. These patterns were not evident by examining the type of burial, such as a weapon grave, nor were they evident in the location of burials in a particular plot. They were visible through a combination of the two types of data. For example, weapon graves within a particular plot or burial area were often the most homogeneous graves in a cemetery. This is compelling evidence and suggests that there may have been familial traditions and kinship relations that underlie patterns within the mortuary spaces. But families are not simple, and it is important to remember that there would have been a significant amount of complexity underpinning this. Indeed, in many burial areas, such as Apple Down's configuration B burials, biological distance may not have been the most important aspect of identity expressed within the mortuary rite. To explore this further, we look at information from teeth metrics. Like individual height, the size and shape of teeth have a strong genetic component. Moreover, in the absence of extensive ancient DNA data, height and teeth metrics are powerful ways to begin a discussion of relatedness within historic population dynamics.

\section{Early Anglo-Saxon teeth metrics}

Teeth provide a strong medium through which to investigate familialinherited traits because their size and shape are derived from genetics (Hughes and Townsend, 2013). Teeth form in early life and they do not remodel like bone, which makes them taphonomically resilient (Galloway et al., 1997). The potential to explore biological inheritance using dental features has been reported before via non-metric characteristics, but has not entered mainstream archaeological analysis because kinship studies have not been fashionable (Alt and Vach, 1991; 1995; Sayer, 2009). Nonetheless, we know that people who are closely related will have 
proportionally similar sized and shaped teeth (Biggerstaff, 1975; Garn, 1977; Townsend and Brown, 1978a). This means that the teeth of sibling children will appear most similar to one another and their parents compared with more distant relatives, and more different still from unrelated individuals (Townsend and Brown, 1978a; 1978b). As a result, it is possible to compare the measurements of individual teeth within cemeteries, and where we assume that there is a similar biological basis to the population we can expect there to be similarly proportioned teeth.

Allison Stewart studied 145 individuals from four cemeteries; fifty-six from Hatherdene, Cherry Hinton, and forty-eight from Oakington (both in Cambridgeshire) as well as twenty-six from Polhill and fifteen from Eastry (both in Kent) (Stewart and Sayer, forthcoming). This created a combined total of 5,988 measurements for statistical analysis, and from this sample it was possible to identify significant patterns of similarity. For example, the left and right mandibular canines had the most significance in their patterning among the Oakington and Hatherdene males (Stewart and Sayer, forthcoming; Table 5.2). Dental metric data were recorded from all identifiable permanent teeth, focusing on skeletons of later adolescence to adulthood. Biologically male and female remains might be better understood together if studied separately, and this provides a useful way to explore sex-based differences within the teeth data. Moreover, there are more factors influencing tooth size than sex alone.

Table 5.2 Observations from cluster analysis for pooled sex comparisons from the combined cemetery and individual cemetery groups: Hatherdene, Oakington, Polhill and Eastry

\begin{tabular}{|c|c|c|c|c|c|c|c|}
\hline Group & $\begin{array}{l}\text { No. of } \\
\text { clusters } \\
\text { at } 1\end{array}$ & $\begin{array}{l}\text { No. of } \\
\text { clusters } \\
\text { at } 3\end{array}$ & $\begin{array}{l}\text { No. of } \\
\text { clusters } \\
\text { at } 5\end{array}$ & $\begin{array}{l}\% \text { of } \\
\text { group } \\
\text { split after } \\
\text { node } 1\end{array}$ & $\begin{array}{l}\text { Distance } \\
\text { of node } \\
2 \text { split }\end{array}$ & $\begin{array}{l}\text { Average } \\
\text { size of } \\
\text { largest } \\
\text { cluster }\end{array}$ & $\begin{array}{l}\text { Proportion } \\
\text { of group } \\
(\%)\end{array}$ \\
\hline $\begin{array}{l}\text { Hatherdene } \\
\text { males }\end{array}$ & 8.5 & 6.50 & 4.50 & 796 & 15 & 4.50 & 205 \\
\hline females & 5.75 & 5.25 & 3.50 & 57.5 & 9.5 & 4.25 & 26.5 \\
\hline $\begin{array}{l}\text { Oakington } \\
\text { males } \\
\text { females }\end{array}$ & $\begin{array}{l}5 \\
6.75\end{array}$ & $\begin{array}{l}4 \\
5.25\end{array}$ & $\begin{array}{l}3 \\
3.75\end{array}$ & $\begin{array}{l}78.9 \\
68.3\end{array}$ & $\begin{array}{c}8 \\
12.25\end{array}$ & $\begin{array}{l}6.50 \\
4.75\end{array}$ & $\begin{array}{l}43.5 \\
27\end{array}$ \\
\hline $\begin{array}{l}\text { Polhill } \\
\text { males } \\
\text { females }\end{array}$ & $\begin{array}{l}5 \\
6.50\end{array}$ & $\begin{array}{l}4 \\
5\end{array}$ & $\begin{array}{l}3 \\
3.50\end{array}$ & $\begin{array}{l}85.7 \\
58.7\end{array}$ & $\begin{array}{l}14 \\
11\end{array}$ & $\begin{array}{l}2 \\
3\end{array}$ & $\begin{array}{l}29 \\
25\end{array}$ \\
\hline $\begin{array}{l}\text { Eastry } \\
\text { males } \\
\text { females }\end{array}$ & $\begin{array}{l}2 \\
3.25\end{array}$ & $\begin{array}{l}2 \\
3.13\end{array}$ & $\begin{array}{l}2 \\
2.63\end{array}$ & $\begin{array}{l}66.7 \\
70.4\end{array}$ & $\begin{array}{l}4 \\
8.38\end{array}$ & $\begin{array}{l}2 \\
2\end{array}$ & $\begin{array}{l}67 \\
49.3\end{array}$ \\
\hline
\end{tabular}


After analysis, clusters were observed (see Table 5.2) and were identified at the squared Euclidean distances of 1, 3 and 5; also identified was the percentage of the group that split after node 1 ; the distance of node 2 split; the average size of largest cluster across all teeth; and the proportion of the sample that this cluster comprised overall. Focusing on significant teeth, a 'hierarchical cluster analysis' (HCA) showed that, at all four sites, males had fewer clusters than females for the same tooth; this pattern was observed across all of the significant teeth identified. Men also appeared to have had more individuals within each cluster than the females did. At each site, there were small numbers of relatively large groups of related males, and a larger number of smaller groups of related females. Such a pattern is very similar to the results described for height data and, where in some burial areas there was less diversity within the male population than in the female population, it would seem that both the height and the teeth data are pointing in the same direction. In these early Anglo-Saxon cemeteries there were more related males than related females. Many of the related males included weapons within their burials; however, caution is needed because membership of a particular family group was evidently not the only reason to have been buried with a weapon. Nonetheless, these two studies imply a high degree of relatedness within the populations of these cemeteries, which tends to suggest that early Anglo-Saxon cemeteries included a familial element. The proportion of related men also suggests that among a particular group there was a strong male residency pattern, which remained; it seems it was women who moved for marriage. As a result, though women and their daughters were related, new women came into the community in each generation - a pattern that would result in small numbers of biologically similar women. Men remained and so each generation contained related men, a result seen in the large groups with high degrees of similarity within the tooth metrics.

Notably, however, in the examples discussed there was not just a single male group or lineage; indeed, the teeth data appear to be structured in such a way as to imply that there were several different communities of people, who shared different degrees of relatedness, within each site. There may have been several groups of males who were related to each other, but also to the women within the community. Indeed, the height data suggest that there was greater homogeneity between the poorly furnished female burials (which were also the smallest); either these individuals had less social worth and so received less food throughout their lives, or the lower social ranks practised female residency whereas men from these groups moved to marry, or for work. Nonetheless, the height and teeth data both suggest that the most homogeneous group within all of these communities were the males, a 
group which contained high degrees of relatedness among the wealthier burial areas within each site. This is especially important because the chronology data described in Chapter 3, suggest that it was to these burial areas that people returned generation after generation to bury their dead.

\section{Conclusion}

The world that people occupy exists independently of their knowledge of it. This is particularly true of biosocial problems, where the impact of lifestyle on the physical bodies of groups may not be known to the individual. Comparably, DNA does not respect the institution of marriage but is the combined product of physical parents whose genes were passed on and expressed in their child. This chapter has looked at evidence of both lifeways and relatedness, and has seen patterns in both types of evidence that correlate with both the organisation of the cemetery space and the expression of material culture.

At the time of writing, the methodologies and questions employed in the investigation of ancient DNA are only just catching up with the problems of social archaeology (Sykes, et al. 2019). However, we have an enormous amount of data to investigate by looking at the bodies of past people and, most importantly, by situating the data within each contextual setting. In this chapter we have used trauma pathology, or physical injury, to look at lifeways. The individual experience is important, but by examining the bodies of individuals it is possible to see patterns in lifestyle that were underpinned by social freedoms or attitudes within groups in each cemetery. Importantly, there seem to have been two basic types of cemetery, those with two or more similarly sized, broadly equal groups with similar lifeways, and those with a single core group and a spectrum of other groups with higher risks of trauma and/or less mortuary wealth. Crucially, in a given cemetery, these patterns were visible within and between groups, and not individual graves. For example, it was not possible to see patterns within weapon graves, because the placement of a weapon within a grave was dependent on a host of different decisions. However, it was possible to distinguish some weapon graves that were buried in a similar location within the cemetery. There were different attitudes towards burying the dead, and each cemetery consisted of a host of different approaches that were competing against the use of material culture or space as a form of differential expression contingent on the individual's identity. These attitudes were simultaneous influences on lifeways, chronology and the expression of the mortuary aesthetic.

Importantly, it is differences in attitude which underpin social difference, not wealth or the resources implied with the grave - which were 
expressions of the individual. This is especially true in archaeological data because the circumstances of death, burial and the disposal of the body vary from one individual to another. To use a well-known example, Richard III was buried without rich gravegoods, in a minor church in the middle of England (King et al., 2014). The circumstance of his death, the shift in political power that resulted from it, and the redistribution of attitudes toward him post mortem may have affected the location and circumstances of his grave. Nonetheless, it was his body and its treatment in life and in death that revealed his identity to archaeologists (Appleby et al., 2015). Similarly, in early Anglo-Saxon cemeteries grave location, wealth and style may have been contingent on the specific social context at the point of burial. The chronological point of the burial, who survived the deceased, the cause of death and/or any social or economic effects of that death would potentially change the material expressions involved in commemoration. The most stable post mortem communities, those which showed similar patterns across the life of the cemetery, comprised those individuals who had suffered least from exposure to the risk of trauma and had the most homogeneity among their teeth and height metrics. Collectively, these groups may have expressed the greatest wealth, even if individually they did not. At the heart of one or two plots in each cemetery seems to have been a multi-generational group of males with very similar statures and teeth metrics. It was these individuals and their immediate social group that returned to a cemetery generation after generation and created high-density burials areas, core groups or rows of graves. Diet, homogeneous or heterogeneous bodies and the lifeways evident in the archaeological record have provided powerful evidence for attitude in the mortuary context. And it is the attitude behind a burial, not the grave wealth within it, which provides us with a holistic approach to social archaeology. Ultimately, attitude may give us good access to questions about social segregation and/or identity. The exploration of personhood should be based on the social context, as well as at the level of the contents of the grave. 